\title{
LA MUJER COMO CARGO Y COMO FUENTE EN LA PRENSA ESCRITA. LA PARIDAD NO LLEGA A LAS NOTICIAS
}

\author{
Ofa Bezunartea Valencia \\ (Universidad del País Vasco) \\ ofa@bezunartea.net \\ María del Mar García Gordillo \\ (Universidad de Sevilla) \\ marggordillo@us.es \\ Ana Rodríguez Rey \\ (Universidad de Sevilla) \\ anarodrey@gmail.com
}

\begin{abstract}
Resumen: La igualdad entre géneros no existe. La Ley 3/2007 pretende corregir desviaciones. Si en la primera línea del poder se cumple con la "Ley de Paridad", en los escalones posteriores, no. Tanto la Ley como la gestión femenina en la vida pública deben tener representación mediática. Este estudio comprueba que si bien la presencia de mujeres se ha incrementado, ocupa un lugar irrisorio en la prensa. El dato más significativo es que las noticias de género o protagonizadas por mujeres representan el $6 \%$ de los textos publicados, lo que corrobora que la paridad, de existir, no tiene reflejo mediático.
\end{abstract}

Palabras claves: Estudios de género, paridad, gestión política, techo de cristal, medios de comunicación.

Abstract: Gender equality does not exists. Law 3/2007 aims to correct deviations. If the first line of power meets the "Parity Act" in the later stages, no. Both the Act and the management of women in public life should be represented in the media. This study proves that although the pre has increased, is at ridiculous in the press. The most significant is that the news genre or featuring women representing $6 \%$ of published texts, which leads confirm that parity, if any, do not get media reflection.

Key Words: Studies of gender, parity, policy management, glass ceiling, mass media.

\section{INTRODUCCIÓN}

I periodismo no ha sido una excepción en la historia de discriminación de género, pese a ser una actividad social con poco más de un siglo de vida y por tanto con marchamo de modernidad. Si la vida profesional, económica, 
La mujer como cargo y como fuente en la prensa escrita.

La paridad no llega a las noticias

política del mundo, no tenía otros protagonistas que los varones, también los medios informativos encargados de dar cuenta de ella eran terreno masculino en la doble faceta de autores de los relatos y de personajes visibles como actores de la inmensa mayoría de los hechos noticiosos. La gran revolución para conseguir que las mujeres fueran simplemente personas, comenzó apenas hace sesenta años. Bogart (1985: 127) señala la década de los 70 cuando el nuevo feminismo se basó en la transformación radical y fundamental del papel que la mujer venía desarrollando tradicionalmente.

Los diversos estudios realizados en épocas recientes han puesto de manifiesto tanto la invisibilidad de la mujer en los medios como la influencia de estereotipos masculinos en los contenidos de los medios de comunicación (Soriano,J., Canton, M.J. y Díez, M. 2005; Blanco Castilla, E. 2005; Bruin, M. y Ross, K. 2004; García de cortázar, M. y García de León M.A., 2000; Mahoney, E., 2000; Van Zoonen, L., 1991; Gallego, J., 2000). Esta invisibilidad en los medios podría estar ligada a la escasez de mujeres en cargos públicos y privados, por ello la irrupción de medidas de discriminación positiva para la mayor presencia de mujeres en cargos de responsabilidad debería tener una fuerte influencia en su reflejo en los medios de comunicación como objeto informativo y como fuente de información. Entre otras muchas iniciativas para cambiar esa realidad se aprobó en España la Ley $3 / 2007$ de 22 de marzo para la igualdad efectiva de hombres y mujeres con la pretensión de acabar con la discriminación existente hasta la fecha. En la llamada Ley de Igualdad se establecen criterios y medidas para evitar la discriminación por motivos de sexo y se hace un llamamiento a los medios de comunicación tanto de titularidad pública como privada. Entre otras medidas se establecen porcentajes de presencia femenina en los organismos públicos no inferiores al $40 \%$, al mismo tiempo que recomienda a las entidades privadas que traten de alcanzar objetivos parecidos.

\section{OBJETO DE ESTUDIO}

El objeto de estudio de este artículo es La presencia de la mujer como cargo y como fuente en la prensa escrita y forma parte de una investigación más amplia "La satisfacción de las necesidades informativas de la mujeres. Análisis de la empresa periodística bajo la perspectiva de género", realizado sobre seis periódicos andaluces con categorías que permitieran medir cualitativa y cuantitativamente el tratamiento de los temas de género y de presencia femenina en las noticias.

La muestra del análisis corresponde a finales de 2009 y comienzos de 2010 y se ha considerado interesante estudiar cómo se reflejaba en los periódicos andaluces la presencia de cargos femeninos nacionales y autonómicos. En abril de 2009 José Luis Rodríguez Zapatero hace una remodelación de su ejecutivo, que a su vez obligó a la remodelación del gobierno andaluz, ya que el presidente Chávez pasó a ocupar la tercera Vicepresidencia del gobierno central. El 22 de Abril de 2009 el nuevo presidente de la Junta de Andalucía nombró un ejecutivo 
con nueve mujeres y seis hombres (este ejecutivo cumplía la ley de igualdad en un porcentaje de 60/40, aplicando el índice superior a las mujeres y el inferior a los hombres). El nacional también cumplía con la paridad. En la misma linea interesa conocer cuál es la presencia femenina en otras instancias institucionales como son los parlamentos, nacional y autonómico, y las alcaldías. Todas ellas constituyen la mayor fuente noticiosa de los medios.

En el Congreso de los diputados en las últimas legislaturas se observa un aumento constante de la presencia femenina sobre el total de Diputados, a pesar de todo la representación femenina no alcanza el $50 \%$.

Gráfico 1. Diputadas españolas por legislatura.

\begin{tabular}{|l|c|c|c|c|c|c|c|}
\hline Legislaturas & $\begin{array}{c}1982 \\
/ 86\end{array}$ & $\begin{array}{c}1986 \\
/ 89\end{array}$ & $\begin{array}{c}1989 \\
/ 93\end{array}$ & $\begin{array}{c}1993 \\
/ 96\end{array}$ & $\begin{array}{c}1996 \\
/ 00\end{array}$ & $\begin{array}{c}2000 \\
/ 04\end{array}$ & $\begin{array}{c}2004 \\
/ 08\end{array}$ \\
\hline $\begin{array}{l}\text { Total Dipu- } \\
\text { tados/as }\end{array}$ & 392 & 394 & 389 & 407 & 409 & 416 & 399 \\
\hline$\%$ Mujeres & $5,87 \%$ & $8,38 \%$ & $13,88 \%$ & $15,97 \%$ & $23,96 \%$ & $31,73 \%$ & $36,59 \%$ \\
\hline
\end{tabular}

Fuente: Instituto de la Mujer.

En 2009, en ministerios el porcentaje es del 50, en secretarías de estado del 25 y en subsecretarías del 26.67. Lo que lleva a pensar que si bien el gobierno socialista se encargó de que en la primera fila las mujeres fueran el $50 \%$ de los cargos, en jerarquías inferiores ocuparon sólo un $25 \%$ de los cargos de responsabilidad lo que supone un claro descenso con respecto al año 2008, en el que ocupaban un $31,25 \%$ de las secretarías de Estado y un 28,77 de las subsecretarías. Esto supondría una relajación en la aplicación de las cuotas establecidas en la ley de 2007.

En el caso de Andalucía y en relación con los altos cargos: de los trece consejeros, seis son mujeres; en viceconsejerías, de trece, tres; y, en secretarías generales, de 19, siete. Esto es como en el gobierno estatal, los índices de presencia femeninas se desploman en las segundas filas de la gestión pública. En cuanto a la administración local la presencia de mujeres al frente de corporaciones municipales andaluzas es aún más negativa.

Estas nuevas políticas institucionales ¿qué reflejo tienen en los medios de comunicación?, ¿significa una mayor presencia de las mujeres en los cargos de toma de decisiones una mayor presencia de las mismas en los medios de comunicación? ¿son todos los cargos de gestión igual de importantes? ¿tienen todos la misma proyección mediática? ¿están las mujeres asociadas a determinadas temáticas en los ámbitos públicos? 
La mujer como cargo y como fuente en la prensa escrita.

La paridad no llega a las noticias

Gráfico 2. Presencia de mujeres y hombres en los Ayuntamientos andaluces.

\begin{tabular}{|l|c|c|c|}
\hline \multicolumn{1}{|c|}{ Provincia } & Mujeres & Hombres & Total \\
\hline Almería & 15 & 87 & 102 \\
\hline Cádiz & 8 & 36 & 44 \\
\hline Córdoba & 20 & 55 & 75 \\
\hline Granada & 29 & 139 & 168 \\
\hline Huelva & 12 & 67 & 97 \\
\hline Jaén & 16 & 81 & 97 \\
\hline Málaga & 14 & 86 & 100 \\
\hline Sevilla & 11 & 94 & 105 \\
\hline Total & 125 & 645 & 770 \\
\hline
\end{tabular}

Fuente: Instituto de la Mujer.

\section{METODOLOGÍA}

La muestra de análisis la componen seis periódicos elegidos tras estudiar los índices de audiencia desagregados por sexos del Estudio General de Medios del año 2009, se seleccionaron los tres más leídos por mujeres, los dos menos leídos puesto que el tercero desapareció, así como el punto medio de la tabla, con la intención de averiguar qué genera esta diferencia en las preferencias de lectura femenina.

Con estos diarios se compuso una semana falsa (K. Krippendorff, 1990; G. Stempel; 1989,1981 ) lo que permite disponer de una muestra no mediatizada por ningún acontecimiento ni contingencia. La muestra comienza el 16 de noviembre de 2009 y termina el domingo 3 de enero de 2010.

La actitud de los periódicos respecto de la mujer puede medirse a través de la técnica de análisis de contenido, considerando su visibilidad, es decir su presencia como protagonista activa o pasiva de noticias y por otra parte la atención que prestan a los temas englobados en el concepto de "género" y que se refieren a todas las peculiaridades de la vida social y política en que se perciben las diferencias de rol entre hombres y mujeres.

Nuestra base de trabajo fueron 42 ejemplares de periódicos que en conjunto publicaron 6.600 noticias. Hicimos fichas de análisis en las que contabilizamos todas las noticias de género y/o con protagonista femenina, así como las firmas de periodistas, las fuentes y la detección de si las protagonistas mujeres aparecían en función de su cargo o profesión. La aplicación de estas fichas se hace 
asignando un número de cada una de las categorías a cada uno de los textos analizados de manera que cada noticia queda reducida a un cúmulo de números (asimilables a las categorías) que procesados a través del programa SPSS generan las tablas de contingencia y resultados que siguen.

\section{RESULTADOS}

La Ley de Igualdad constituye una transcendental apuesta institucional para forzar el camino a la paridad entre sexos al menos en los organismos públicos. Aún así, como lo prueban los resultados expuestos, no se llega a cumplir la representación exigida por la ley. Y los avances en la linea de la equiparación entre hombres y mujeres en el ámbito privado son notablemente más lentos. $Y$ prácticamente no hay excepciones, cualquiera que sea la actividad que se analice.

Aunque en el periodismo, en la composición de las plantillas, ha aumentado el número de redactoras, sigue estando pendiente el equilibrio de sexos en los puestos de responsabilidad. Otra cosa es el capítulo de contenidos. Precisamente el objeto del análisis es conocer qué grado de equilibrio informativo en cuanto a la presencia de ambos sexos se da en los seis diarios andaluces elegidos para el estudio. Se comprobará cómo ejercen su papel de espejo de la sociedad, qué presencia y protagonismo tienen las mujeres en sus páginas, qué interés prestan a los temas de género, considerando como tales los relacionados con las peculiaridades de la vida social y política en las que se perciben las diferencias de rol entre hombres y mujeres y qué rango profesional asignan a las periodistas que trabajan en sus redacciones.

Ya en los trazos gruesos, los resultados demuestran que la imagen que transmiten los diarios no muestran que la sociedad esté compuesta por hombres y mujeres más o menos al $50 \%$ o acaso que los acontecimientos importantes que ocurren están mayoritariamente protagonizados por hombres.

Los textos que tratan temas de los que se han denominado noticias de genero o cuya protagonista es femenina, apenas representan el $6 \%$ del total de noticias y las fotos y firmas de periodistas se quedan en un $12 \%$ sobre el total de textos publicados como se aprecia en el gráfico.

Gráfico 3. Resultados totales.

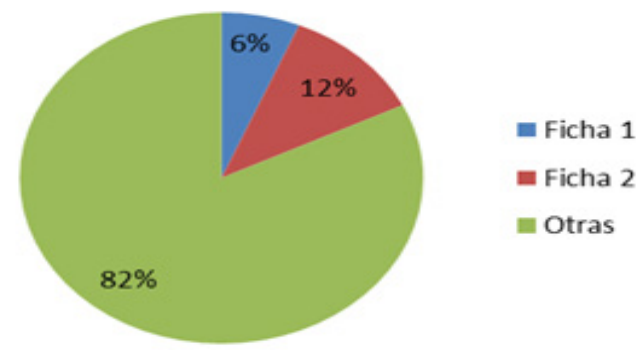

Fuente: Elaboración propia. 
La mujer como cargo y como fuente en la prensa escrita.

La paridad no llega a las noticias

\subsection{Noticias con tema de género y/o protagonista femenina}

Gráfico 4. Noticias con tema de género y/o protagonista femenina.

\begin{tabular}{|c|c|c|c|c|c|c|c|}
\hline TEMAS & $\begin{array}{l}\text { El Correo } \\
\text { de And. }\end{array}$ & $\begin{array}{l}\text { Diario de } \\
\text { Sevilla }\end{array}$ & $\begin{array}{c}\text { Málaga } \\
\text { Hoy }\end{array}$ & $\begin{array}{l}\text { La Voz de } \\
\text { Cádiz }\end{array}$ & $\begin{array}{l}\text { Huelva In- } \\
\text { formación }\end{array}$ & $\begin{array}{c}\text { Granada } \\
\text { Hoy }\end{array}$ & Promedio \\
\hline Político & $18,99 \%$ & $25,00 \%$ & $17,50 \%$ & $21,05 \%$ & $17,95 \%$ & $12,12 \%$ & $19,44 \%$ \\
\hline Sucesos & $3,80 \%$ & $2,94 \%$ & $0,00 \%$ & $0,00 \%$ & $1,28 \%$ & $6,06 \%$ & $2,25 \%$ \\
\hline Salud & $5,06 \%$ & $0,00 \%$ & $0,00 \%$ & $1,75 \%$ & $2,56 \%$ & $0,00 \%$ & $1,97 \%$ \\
\hline $\begin{array}{l}\text { Vida do- } \\
\text { méstica }\end{array}$ & $0,00 \%$ & $1,47 \%$ & $0,00 \%$ & $0,00 \%$ & $1,28 \%$ & $0,00 \%$ & $0,56 \%$ \\
\hline Economía & $3,80 \%$ & $0,00 \%$ & $0,00 \%$ & $3,51 \%$ & $0,00 \%$ & $0,00 \%$ & $1,41 \%$ \\
\hline Vida social & $8,86 \%$ & $16,18 \%$ & $10,00 \%$ & $7,02 \%$ & $19,23 \%$ & $36,36 \%$ & $14,93 \%$ \\
\hline Justicia & $0,00 \%$ & $0,00 \%$ & $0,00 \%$ & $3,51 \%$ & $0,00 \%$ & $0,00 \%$ & $0,56 \%$ \\
\hline Educación & $3,80 \%$ & $0,00 \%$ & $0,00 \%$ & $3,51 \%$ & $1,28 \%$ & $0,00 \%$ & $1,69 \%$ \\
\hline Laboral & $2,53 \%$ & $2,94 \%$ & $2,50 \%$ & $0,00 \%$ & $0,00 \%$ & $0,00 \%$ & $1,41 \%$ \\
\hline Ciencia & $0,00 \%$ & $0,00 \%$ & $0,00 \%$ & $1,75 \%$ & $0,00 \%$ & $0,00 \%$ & $0,28 \%$ \\
\hline Deportes & $1,27 \%$ & $10,29 \%$ & $5,00 \%$ & $7,02 \%$ & $16,67 \%$ & $9,09 \%$ & $8,45 \%$ \\
\hline Cultura & $26,58 \%$ & $17,65 \%$ & $22,50 \%$ & $24,56 \%$ & $12,82 \%$ & $3,03 \%$ & $18,87 \%$ \\
\hline $\begin{array}{l}\text { Concilia- } \\
\text { ción }\end{array}$ & $0,00 \%$ & $0,00 \%$ & $0,00 \%$ & $0,00 \%$ & $1,28 \%$ & $0,00 \%$ & $0,28 \%$ \\
\hline $\begin{array}{l}\text { Violencia } \\
\text { Género }\end{array}$ & $7,59 \%$ & $17,65 \%$ & $5,00 \%$ & $5,26 \%$ & $6,41 \%$ & $18,18 \%$ & $9,58 \%$ \\
\hline $\begin{array}{l}\text { Med. } \\
\text { Com. }\end{array}$ & $3,80 \%$ & $0,00 \%$ & $2,50 \%$ & $3,51 \%$ & $5,13 \%$ & $6,06 \%$ & $3,38 \%$ \\
\hline $\begin{array}{l}\text { Humanita- } \\
\text { rismo }\end{array}$ & $3,80 \%$ & $0,00 \%$ & $7,50 \%$ & $0,00 \%$ & $3,85 \%$ & $0,00 \%$ & $2,54 \%$ \\
\hline $\begin{array}{l}\text { Prostitu- } \\
\text { ción }\end{array}$ & $0,00 \%$ & $1,47 \%$ & $0,00 \%$ & $0,00 \%$ & $0,00 \%$ & $0,00 \%$ & $0,28 \%$ \\
\hline Género & $10,13 \%$ & $4,41 \%$ & $22,50 \%$ & $17,54 \%$ & $8,97 \%$ & $9,09 \%$ & $11,27 \%$ \\
\hline Religión & $0,00 \%$ & $0,00 \%$ & $5,00 \%$ & $0,00 \%$ & $1,28 \%$ & $0,00 \%$ & $0,85 \%$ \\
\hline
\end{tabular}

\section{1- Noticias con tema de género y/o protagonista femenina}

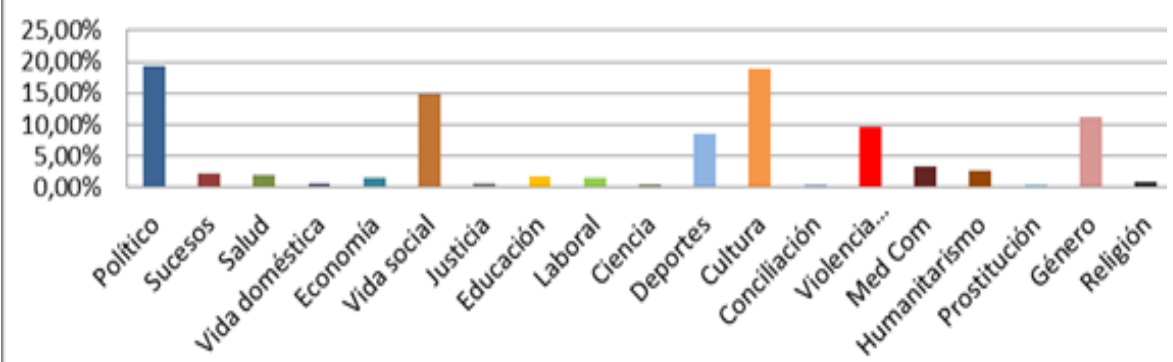

Fuente: Elaboración propia. 
Este gráfico representa la síntesis de cómo se distribuye en los medios la temática relativa a los temas de género y al protagonismo femenino en las noticias, sin perder de vista que se habla de un bloque temático que apenas representa el $6,29 \%$ del total de noticias en la prensa y que estos datos se refieren exclusivamente al bloque de noticias analizado. El tema que arrastra mayor presenciade ambas cuestiones es la política con un $19 \%$ de media, lo cual se correspondería con el hecho de que, aunque no se hayan cumplido las proporciones que la Ley de Paridad imponía, es la actividad en la que la presencia de mujeres en puestos de responsabilidad es más alto. Hay diferencias notables entre los periódicos: desde el $25 \%$ en El Diario de Sevilla al $12 \%$ de Granada Hoy. El tema que ocupa el segundo lugar es el de cultura con el $18,8 \%$, pero el relativamente alto porcentaje se debe en el tema se incluye el mundo del espectáculo, donde las estrellas constituyen un notable "gancho" periodístico. Algo similar ocurre con el $14,9 \%$ del capítulo vida social, que tiene que ver más con el "cotilleo" que con la verdadera relevancia social y que, por cierto es una temática que apenas tenía presencia hace unos años en la prensa de información general, pero que ha irrumpido en ella sin duda por el efecto arrastre de los programas del "corazón" de notable éxito televisivo. Los temas de género, en la media de periódicos queda el $11,2 \%$; todavía es más bajo el relativo a violencia de género, el 9,5\%, pese a la tremenda lacra social que se refleja en las más de 60 mujeres asesinadas por sus pareja cada año y pese también a las numerosas acciones de la administración tratando de evitarla. Los temas relativos a educación, economía o conciliación tienen una presencia irrelevante ya en este bloque específico, si lo refiriéramos al periódico en general (15,8 veces menos) la proporción es tan ridícula que casi produce sonrojo.

\subsection{Noticias de género o con mujeres como objeto informativo por sec ciones}


La paridad no llega a las noticias

Gráfico 5. Noticias de género o con mujeres como objeto informativo por secciones.

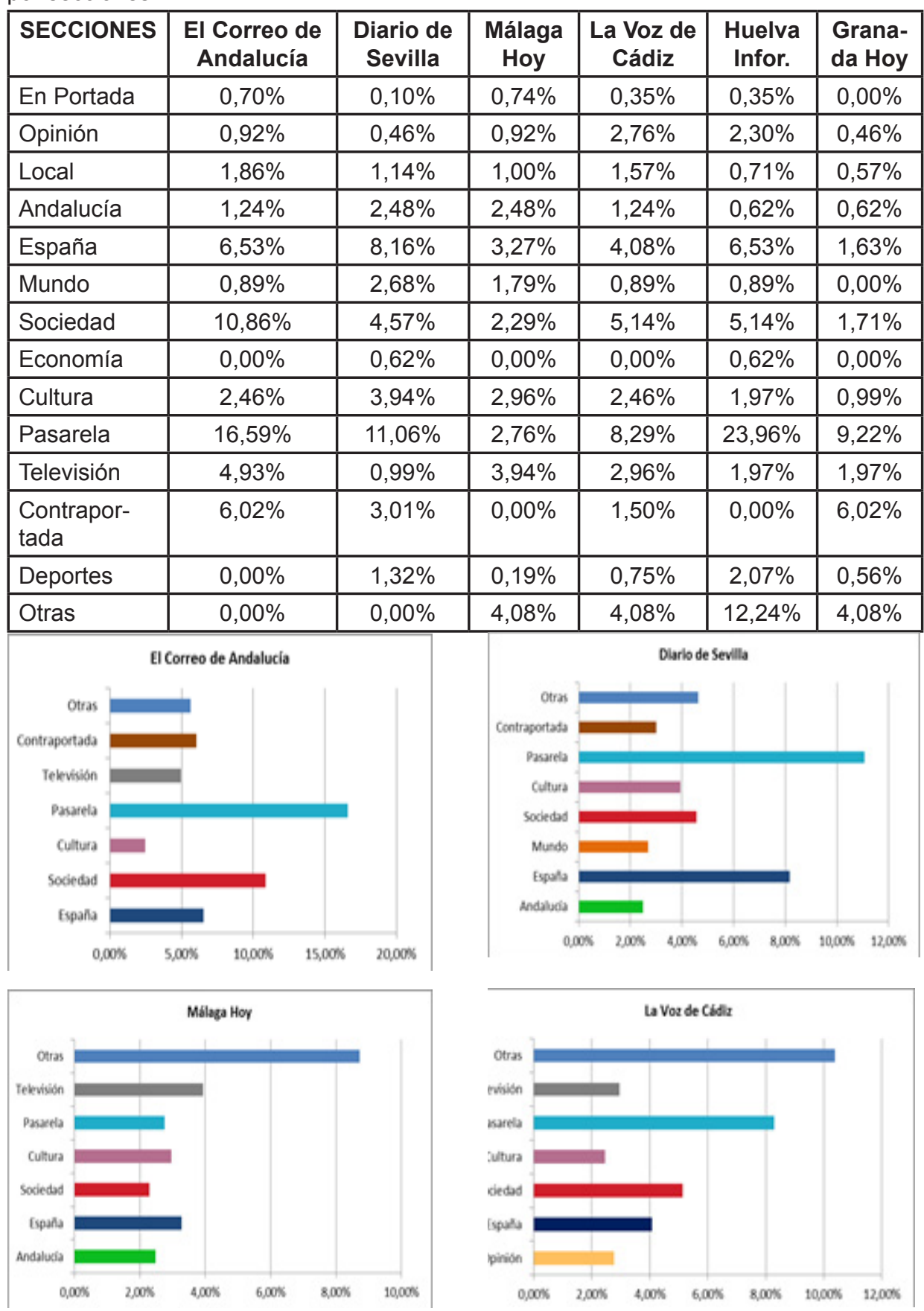


Ofa Bezunartea Valencia, Ma del Mar García Gordillo, Ana Rodríguez 241

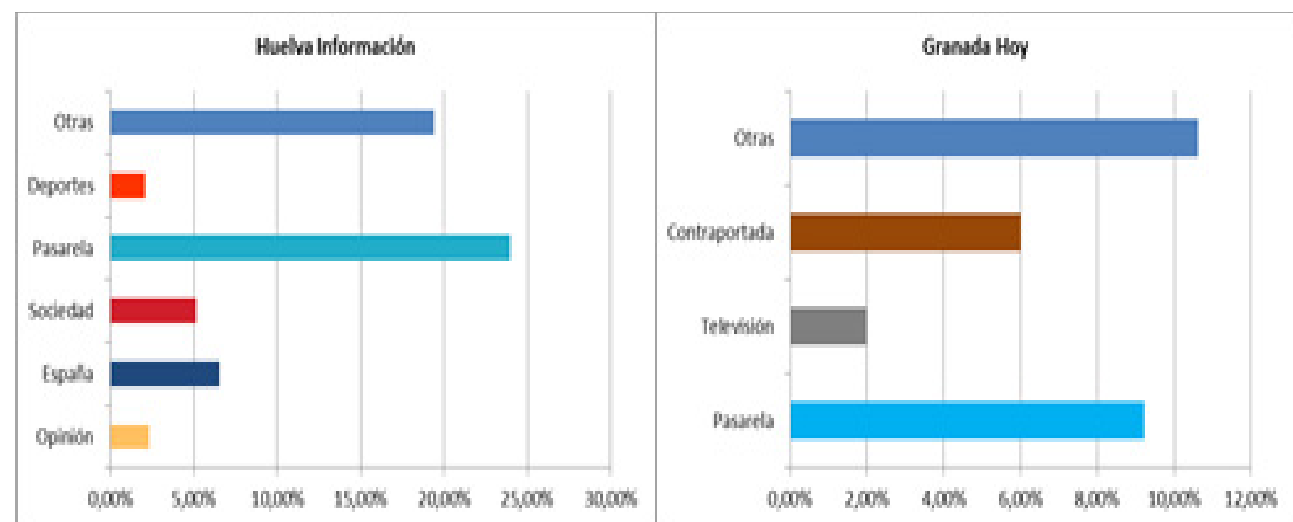

Fuente. Elaboración propia.

El análisis de las secciones es redundante respecto de los temas, pero es muy significativo en la medida que refleja cómo en las de más peso, las que se consideran el plato fuerte de los periódicos por contener los temas más serios y relevantes, los temas de género y protagonismo femenino son testimoniales. Se ha respetado la denominación que se da a las secciones en los periódicos, en el caso de que determinadas secciones tuvieran distinta nomenclatura se ha optado por una denominación genérica, como es Vida Social. Es el caso de la primera página o portada que nunca llega al $1 \%$, cuando no está en el cero como ocurre en Granada Hoy; todavía es más llamativo en economía, donde cuatro de los seis periódicos marcan el cero y sólo Diario de Sevilla y Huelva Información alcanzan un exiguo $0,62 \%$. Resulta llamativo que en los temas locales, que por otra parte están entre los de mayor interés de las lectoras por tratar las cuestiones más próximas, también sea irrelevante la presencia femenina, aunque se aprecien algunas diferencias entre los distintos periódicos: del $0,57 \%$ de Granada Hoy al 1,86 de El Correo de Andalucía. Excepto en el caso del diario granadino, con un 1,63\%, en los otros diarios andaluces se observan mayores referencias a temas de género o protagonismo femenino en la sección de España: en el Diario de Sevilla alcanza el $8,16 \%$ y en El Correo de Andalucía y Huelva información el 6,53\%. Lo cual es sin duda achacable a la notable proporción de mujeres en la política institucional y de partidos. 
La mujer como cargo y como fuente en la prensa escrita.

La paridad no llega a las noticias

\begin{tabular}{|l|c|c|c|c|c|}
\hline & Sin protag. & $\begin{array}{c}\text { Protag } \\
\text { activa }\end{array}$ & $\begin{array}{c}\text { Protag } \\
\text { pasiva }\end{array}$ & $\begin{array}{c}\text { Secun- } \\
\text { daria }\end{array}$ & Víctima \\
\hline Diario de Sev. & $2,25 \%$ & $15,73 \%$ & $3,37 \%$ & $0,00 \%$ & $0,84 \%$ \\
\hline Voz de Cádiz & $0,00 \%$ & $14,89 \%$ & $3,37 \%$ & $0,00 \%$ & $0,84 \%$ \\
\hline Correo And. & $1,97 \%$ & $5,90 \%$ & $1,40 \%$ & $0,00 \%$ & $1,97 \%$ \\
\hline Málaga Hoy & $2,53 \%$ & $8,99 \%$ & $3,37 \%$ & $0,56 \%$ & $0,84 \%$ \\
\hline Huelva Infor. & $3,65 \%$ & $12,36 \%$ & $3,93 \%$ & $0,56 \%$ & $1,40 \%$ \\
\hline Granada Hoy & $1,97 \%$ & $3,37 \%$ & $2,25 \%$ & $0,28 \%$ & $1,40 \%$ \\
\hline
\end{tabular}

Gráfico 6. Protagonista titulares por diario.

Sobre el tipo actitud de las mujeres que se reflejan en los titulares de los temas de género predominan de un modo muy claro las protagonistas activas, más de un $60 \%$, como actor pasivo apenas representan al $19 \% \mathrm{y}$, en contra de nuestras hipótesis de partida, son muy poco numerosas las protagonistas a título de víctimas (de violencia de género), acaso porque los nombres propios no aparecen en los titulares.

\subsection{Fuentes femeninas}

Gráfico 7. Fuentes femeninas por diario.

\begin{tabular}{|l|c|c|c|c|c|c|c|}
\hline FUENTES & $\begin{array}{c}\text { El Correo } \\
\text { de And. }\end{array}$ & $\begin{array}{c}\text { Diario de } \\
\text { Sevilla }\end{array}$ & $\begin{array}{c}\text { Málaga } \\
\text { Hoy }\end{array}$ & $\begin{array}{c}\text { La Voz } \\
\text { de Cádiz }\end{array}$ & $\begin{array}{c}\text { Huelva } \\
\text { Infor. }\end{array}$ & $\begin{array}{c}\text { Grana- } \\
\text { da Hoy }\end{array}$ & Promedio \\
\hline Sin fuente & $20,25 \%$ & $27,94 \%$ & $27,50 \%$ & $55,17 \%$ & $56,41 \%$ & $66,67 \%$ & $42,32 \%$ \\
\hline Femenina & $51,90 \%$ & $45,59 \%$ & $47,50 \%$ & $25,86 \%$ & $30,77 \%$ & $9,09 \%$ & $35,11 \%$ \\
\hline Masculina & $15,19 \%$ & $10,29 \%$ & $10,00 \%$ & $8,62 \%$ & $8,97 \%$ & $15,15 \%$ & $11,36 \%$ \\
\hline $\begin{array}{l}\text { Sin identi- } \\
\text { ficar }\end{array}$ & $12,66 \%$ & $14,71 \%$ & $15,00 \%$ & $10,34 \%$ & $3,85 \%$ & $9,09 \%$ & $10,09 \%$ \\
\hline \hline
\end{tabular}

El Correo de Andalucía

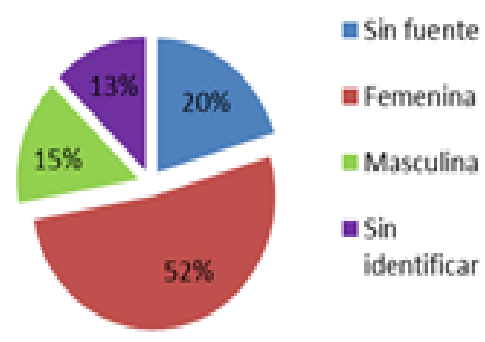

Diario de Sevilla

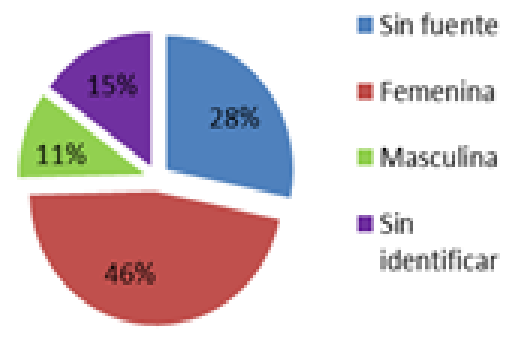


Ofa Bezunartea Valencia, Ma del Mar García Gordillo, Ana Rodríguez 243
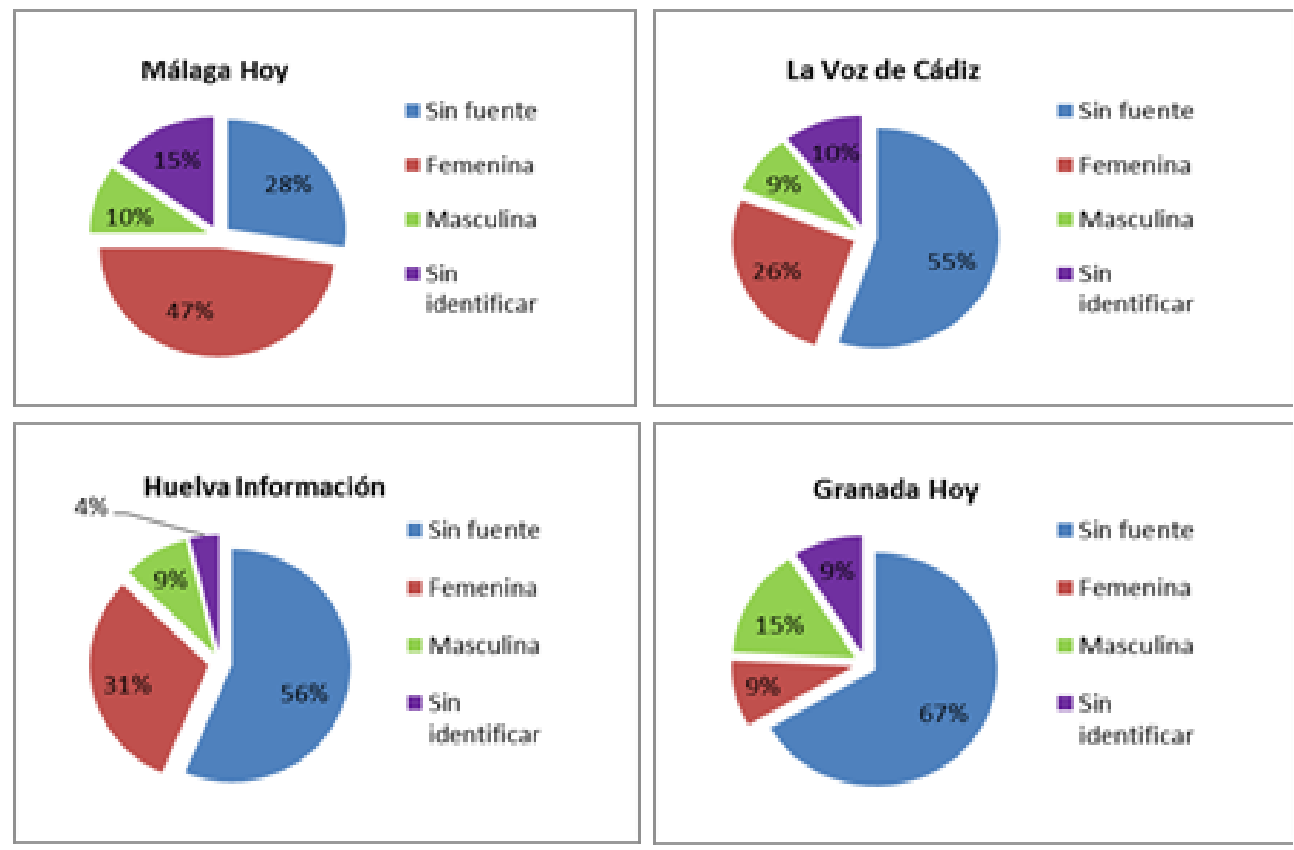

Fuente. Elaboración propia.

Los estudios sobre la falta de visibilidad de la mujer en los medios indican que está relegada como fuente de información lo que supone una clara muestra de la falta de reconocimiento hacia las mujeres. Son muchos ya los campos y actividades: universidad, ciencia, medicina, justicia, por mencionar alguno de los más relevantes, con alta proporción de mujeres y en puestos importantes. Por otra parte las instituciones relacionadas con la paridad y la violencia de género están dirigidas casi exclusivamente por profesionales femeninas. Pues bien, a pesar de todo ello no hay una representación proporcional de mujeres como fuentes de información, ni siquiera en estos temas tan específicos.

Queda patente en el estudio, como puede verse en los gráficos que a pesar de tratarse de noticias de género o con protagonismo femenino, sólo en un diario $\mathrm{El}$ Correo de Andalucía, tienen como fuente a mujeres en un 51,9 \%; Diario de Sevilla y Málaga Hoy dan también porcentajes aceptables: 45,5 y 47,5 respectivamente, sin embargo La Voz de Cádiz , 25,8; Huelva Información, 30,7 y Granada Hoy, 9,0 aportan porcentajes muy bajos. Los porcentajes de fuentes masculinas, aunque muy inferiores a las femeninas, representan cifras muy estimables. Ciertamente tampoco se debe menospreciar el hecho de que haya cada vez más varones que se han incorporado a la defensa de la paridad en la representación de ambos sexos y al reconocimiento de la discriminación de la mujer.

No obstante es significativa la proporción de noticias en las que no se menciona ninguna fuente: en la media de los periódicos es el porcentaje más alto, si bien las diferencias entre periódicos son importantes: entre el 20,2\% de El Correo de Andalucía y el $66,6 \%$ de Granada Hoy. Puesto que la cantidad y calidad de 
La mujer como cargo y como fuente en la prensa escrita.

La paridad no llega a las noticias

las fuentes es determinante de la calidad periodística, estos datos suponen una calificación sintomática de los diarios analizados. En el siguiente gráfico se aprecia el promedio de fuentes femeninas en las noticias de género y protagonizadas por mujeres.

Gráfico 8. Peso de la firma femenina.

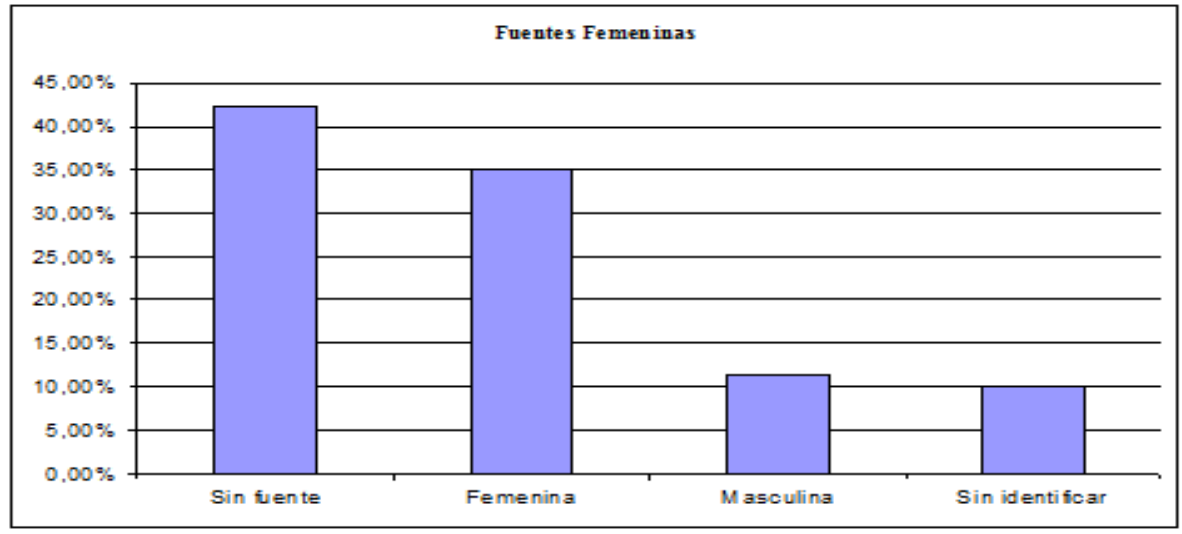

Fuente: Elaboración propia.

\subsection{Menciones de profesiones en las noticias}

Gráfico 9. Profesiones femeninas en los medios.

\begin{tabular}{|l|c|c|c|c|c|c|c|}
\hline FUENTES & $\begin{array}{c}\text { El Correo de } \\
\text { Andalucía }\end{array}$ & $\begin{array}{c}\text { Diario de } \\
\text { Sevilla }\end{array}$ & $\begin{array}{c}\text { Málaga } \\
\text { Hoy }\end{array}$ & $\begin{array}{c}\text { La Voz } \\
\text { de Cádiz }\end{array}$ & $\begin{array}{c}\text { Huelva } \\
\text { Infor. }\end{array}$ & $\begin{array}{c}\text { Granada } \\
\text { Hoy }\end{array}$ & Promedio \\
\hline Sin fuentes & $89,87 \%$ & $83,82 \%$ & $67,50 \%$ & $82,76 \%$ & $84,62 \%$ & $87,88 \%$ & $82,74 \%$ \\
\hline Femenina & $3,80 \%$ & $10,29 \%$ & $10,00 \%$ & $12,07 \%$ & $3,85 \%$ & $6,06 \%$ & $7,67 \%$ \\
\hline Masculina & $6,33 \%$ & $4,41 \%$ & $17,50 \%$ & $5,17 \%$ & $8,97 \%$ & $3,03 \%$ & $7,56 \%$ \\
\hline Sin identificar & $0,00 \%$ & $1,47 \%$ & $5,00 \%$ & $0,00 \%$ & $2,56 \%$ & $3,03 \%$ & $2,01 \%$ \\
\hline
\end{tabular}

Fuente: Elaboración propia.

En qué medida los medios son reflejo de la sociedad es discutible, pero lo cierto es que el mundo que muestran es desproporcionadamente masculinizado. Hemos visto cómo los temas relacionados con el género y con protagonistas femeninas apenas alcanza de media el seis por ciento. La visibilidad femenina resulta llamativamente baja, pero ¿refleja al menos aquellos ámbitos profesionales en los que la mujer ha alcanzado un notable nivel de paridad, como la política, la medicina, la judicatura o la universidad? Nada más lejos, el espacio público sigue siendo casi exclusivamente masculino. Así, entre las profesionales mencionadas, son las artistas, con el $25,1 \%$ las más representadas y si les sumamos el $4,1 \%$ de modelos y el 2,8 \% de "famosas", se aprecia que el interés de los periódicos 
tiene que ver más con el atractivo del impacto, bien sea de la imagen o de las vidas privadas de las estrellas, que con aquellos temas que se relacionan con cuestiones transcendentales: si se habla de profesionales, estrellas y famosas representan más de un tercio de las mujeres que con nombre y apellido aparecen en las páginas de los periódicos. La siguiente profesión más mencionada es la política que llega al $19,7 \%$, no obstante, debemos considerarla como una baja representación si tenemos en cuenta que la vida institucional, en la que la ley de paridad obliga a una fuerte presencia femenina, es una de las de mayor presencia en los periódicos, sea en el ámbito local, autonómico o nacional. La excesiva "institucionalización" es una de las críticas más frecuentes al modelo de producción informativa de los medios.

Tampoco las deportistas merecen atención, como lo prueba ese 9,3 de profesionales mencionadas. Por lo demás, las profesiones de enseñante, sanitaria, funcionaria, ONG, ama de casa, empresaria, abogada, juez, famosa, científica, escritora, periodista, no alcanzan el $3 \%$ de representación en este bloque informativo "femenino" que apenas representa el $6 \%$ del contenido total del periódico, lo que significa que los porcentajes de visibilidad de las mujeres profesionales se mide en centésimas.

Gráfico 10. Protagonistas femeninas de los titulares según medio.

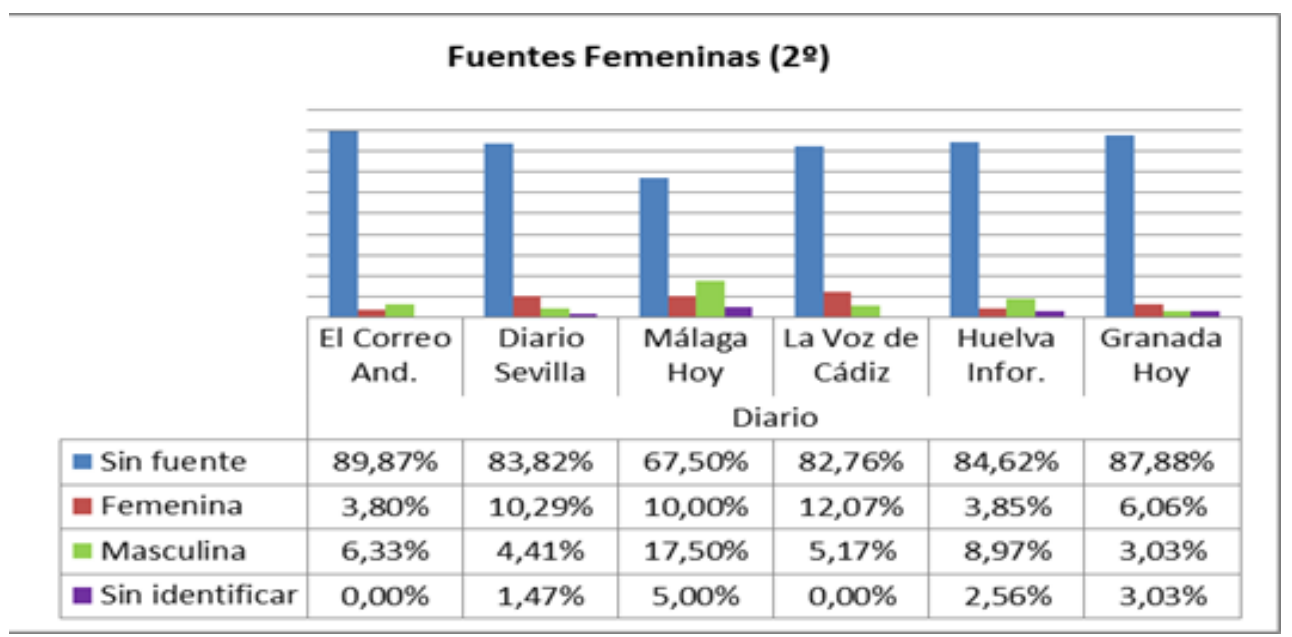

Fuente: Elaboración propia.

Desde el punto de vista de en qué actitudes aparecen en los titulares las mujeres protagonistas de noticias de género, destaca la alta proporción de protagonistas activas que superan el $64 \%$; las pasivas no llegan al 20\%. Sí llama la atención el escaso reflejo en los titulares de protagonistas víctimas a pesar de que en Andalucía se han dado numerosos crímenes de violencia de género.

Por otro lado, el reparto profesional en la representación de actitudes, refleja la mayor proporción de políticas, aunque la categoría "artistas" también en este campo 
La mujer como cargo y como fuente en la prensa escrita.

La paridad no llega a las noticias

deja notar el fuerte peso que representan en las noticias de género.

Gráfico 11: Titulares, protagonistas.

\begin{tabular}{|c|c|c|c|c|c|c|c|}
\hline & $\begin{array}{c}\text { El Correo de } \\
\text { Andalucía }\end{array}$ & $\begin{array}{l}\text { Diario de } \\
\text { Sevilla }\end{array}$ & $\begin{array}{c}\text { Málaga } \\
\text { Hoy }\end{array}$ & $\begin{array}{l}\text { La Voz de } \\
\text { Cádiz }\end{array}$ & $\begin{array}{l}\text { Huelva } \\
\text { Infor. }\end{array}$ & $\begin{array}{c}\text { Granada } \\
\text { Hoy }\end{array}$ & TOTAL \\
\hline Sin profesión & $18,99 \%$ & $23,53 \%$ & $22,50 \%$ & $22,41 \%$ & $20,51 \%$ & $6,06 \%$ & $19,00 \%$ \\
\hline Política & $25,32 \%$ & $22,06 \%$ & $15,00 \%$ & $32,76 \%$ & $20,51 \%$ & $3,03 \%$ & $19,78 \%$ \\
\hline Enseñante & $0,00 \%$ & $2,94 \%$ & $0,00 \%$ & $0,00 \%$ & $2,56 \%$ & $3,03 \%$ & $1,42 \%$ \\
\hline Deportista & $16,46 \%$ & $1,47 \%$ & $7,50 \%$ & $6,90 \%$ & $2,56 \%$ & $21,21 \%$ & $9,35 \%$ \\
\hline Artista & $24,05 \%$ & $22,06 \%$ & $20,00 \%$ & $22,41 \%$ & $28,21 \%$ & $33,33 \%$ & $25,01 \%$ \\
\hline Sanitario & $1,27 \%$ & $4,41 \%$ & $2,50 \%$ & $0,00 \%$ & $2,56 \%$ & $3,03 \%$ & $2,30 \%$ \\
\hline Funcionario & $0,00 \%$ & $4,41 \%$ & $2,50 \%$ & $0,00 \%$ & $0,00 \%$ & $0,00 \%$ & $1,15 \%$ \\
\hline ONG & $0,00 \%$ & $2,94 \%$ & $0,00 \%$ & $1,72 \%$ & $2,56 \%$ & $0,00 \%$ & $1,20 \%$ \\
\hline Ama de casa & $0,00 \%$ & $0,00 \%$ & $0,00 \%$ & $0,00 \%$ & $1,28 \%$ & $6,06 \%$ & $1,22 \%$ \\
\hline Empresaria & $0,00 \%$ & $0,00 \%$ & $0,00 \%$ & $0,00 \%$ & $2,56 \%$ & $6,06 \%$ & $1,44 \%$ \\
\hline Abogada & $0,00 \%$ & $1,47 \%$ & $0,00 \%$ & $1,72 \%$ & $2,56 \%$ & $0,00 \%$ & $0,96 \%$ \\
\hline Juez & $0,00 \%$ & $0,00 \%$ & $0,00 \%$ & $1,72 \%$ & $3,85 \%$ & $0,00 \%$ & $0,93 \%$ \\
\hline $\begin{array}{l}\text { Denomina- } \\
\text { ción vicaria }\end{array}$ & $5,06 \%$ & $1,47 \%$ & $7,50 \%$ & $1,72 \%$ & $0,00 \%$ & $0,00 \%$ & $2,63 \%$ \\
\hline Prostitución & $0,00 \%$ & $0,00 \%$ & $2,50 \%$ & $0,00 \%$ & $0,00 \%$ & $0,00 \%$ & $0,42 \%$ \\
\hline Delincuente & $0,00 \%$ & $0,00 \%$ & $0,00 \%$ & $0,00 \%$ & $1,28 \%$ & $0,00 \%$ & $0,21 \%$ \\
\hline Famoso & $1,27 \%$ & $2,94 \%$ & $2,50 \%$ & $0,00 \%$ & $1,28 \%$ & $9,09 \%$ & $2,85 \%$ \\
\hline Científica & $1,27 \%$ & $1,47 \%$ & $5,00 \%$ & $1,72 \%$ & $3,85 \%$ & $0,00 \%$ & $2,22 \%$ \\
\hline Escritora & $0,00 \%$ & $1,47 \%$ & $2,50 \%$ & $0,00 \%$ & $0,00 \%$ & $0,00 \%$ & $0,66 \%$ \\
\hline Modelo & $3,80 \%$ & $1,47 \%$ & $7,50 \%$ & $5,17 \%$ & $1,28 \%$ & $6,06 \%$ & $4,21 \%$ \\
\hline Periodista & $2,53 \%$ & $5,88 \%$ & $2,50 \%$ & $1,72 \%$ & $2,56 \%$ & $3,03 \%$ & $3,04 \%$ \\
\hline
\end{tabular}

Profesiones femeninas en los medios

Fuente: Elaboración propia. 
Ofa Bezunartea Valencia, Ma del Mar García Gordillo, Ana Rodríguez 247

\subsection{Tema y profesión}

Gráfico 12: Resumen de temas y profesiones.

\begin{tabular}{|l|c|c|c|c|c|c|c|}
\hline & \multicolumn{6}{|c|}{ Diario } & Prome- \\
\cline { 2 - 7 } & $\begin{array}{c}\text { El Correo } \\
\text { de And. }\end{array}$ & $\begin{array}{c}\text { Diario de } \\
\text { Sevilla }\end{array}$ & $\begin{array}{c}\text { Málaga } \\
\text { Hoy }\end{array}$ & $\begin{array}{c}\text { La Voz de } \\
\text { Cádiz }\end{array}$ & $\begin{array}{c}\text { Huelva } \\
\text { Infor. }\end{array}$ & $\begin{array}{c}\text { Granada } \\
\text { Hoy }\end{array}$ & \\
\hline $\begin{array}{l}\text { Sin } \\
\text { protag }\end{array}$ & $11,39 \%$ & $7,35 \%$ & $5,00 \%$ & $5,17 \%$ & $11,54 \%$ & $3,03 \%$ & $7,25 \%$ \\
\hline $\begin{array}{l}\text { Prot. } \\
\text { ctiva }\end{array}$ & $62,03 \%$ & $58,82 \%$ & $55,00 \%$ & $63,79 \%$ & $73,08 \%$ & $75,76 \%$ & $64,75 \%$ \\
\hline $\begin{array}{l}\text { Prot. } \\
\text { Pasiva }\end{array}$ & $16,46 \%$ & $25,00 \%$ & $27,50 \%$ & $24,14 \%$ & $8,97 \%$ & $15,15 \%$ & $19,54 \%$ \\
\hline $\begin{array}{l}\text { Secun- } \\
\text { dario }\end{array}$ & $5,06 \%$ & $1,47 \%$ & $7,50 \%$ & $1,72 \%$ & $2,56 \%$ & $0,00 \%$ & $3,05 \%$ \\
\hline Víctima & $5,06 \%$ & $7,35 \%$ & $5,00 \%$ & $5,17 \%$ & $3,85 \%$ & $6,06 \%$ & $5,42 \%$ \\
\hline
\end{tabular}

Tabla 7. Protagonistas femeninas de los titulares según medio.

Fuente: Elaboración propia.

Las tablas reflejan cómo hacen corresponder los medios las profesiones de las mujeres que aparecen en sus noticias y los temas que tratan. Aunque pueda parecer un análisis un tanto rebuscado, la realidad es que los resultados ponen de manifiesto algunos de los estereotipos periodísticos. Por ejemplo: más artistas que políticas en el tema de política. Aunque debemos hacer constar que este desequilibrio tiene algo de coyuntural por los acontecimientos que coincidieron con el período analizado (las movilizaciones de artistas en apoyo a las reivindicaciones de Aminatu Haidar), tal proceder se refuerza con el tema de violencia de género que se relaciona más con artistas, políticas, incluso deportistas que con amas de casa (la mayoría de las víctimas) juezas, abogadas... Ama de casa aunque de hecho haya que considerarla más una actividad que una profesión, lo cierto es que puede ser asimilada a ese concepto perfectamente sobre todo si se la analiza en función de las numerosas relaciones que suscita: conciliación, dependencia, educación, por ejemplo como temas de actualidad. Pues bien, ama de casa no aparece relacionada con vida doméstica; es más este ámbito queda sólo mencionado con relación a la profesión de artista.

Volviendo a los estereotipos periodísticos, es llamativo que la profesión más relacionada con todas las actividades es la de artista, más incluso que la política, lo cual significa que para los medios las artistas interesan como fuente o referencia no por su especialidad profesional sino por el gancho periodístico. 
La mujer como cargo y como fuente en la prensa escrita.

La paridad no llega a las noticias

\subsection{Temas de género: personificación femenina por cargo y profesión}

Gráfico 13: Cruce de mujeres según cargo y profesión.

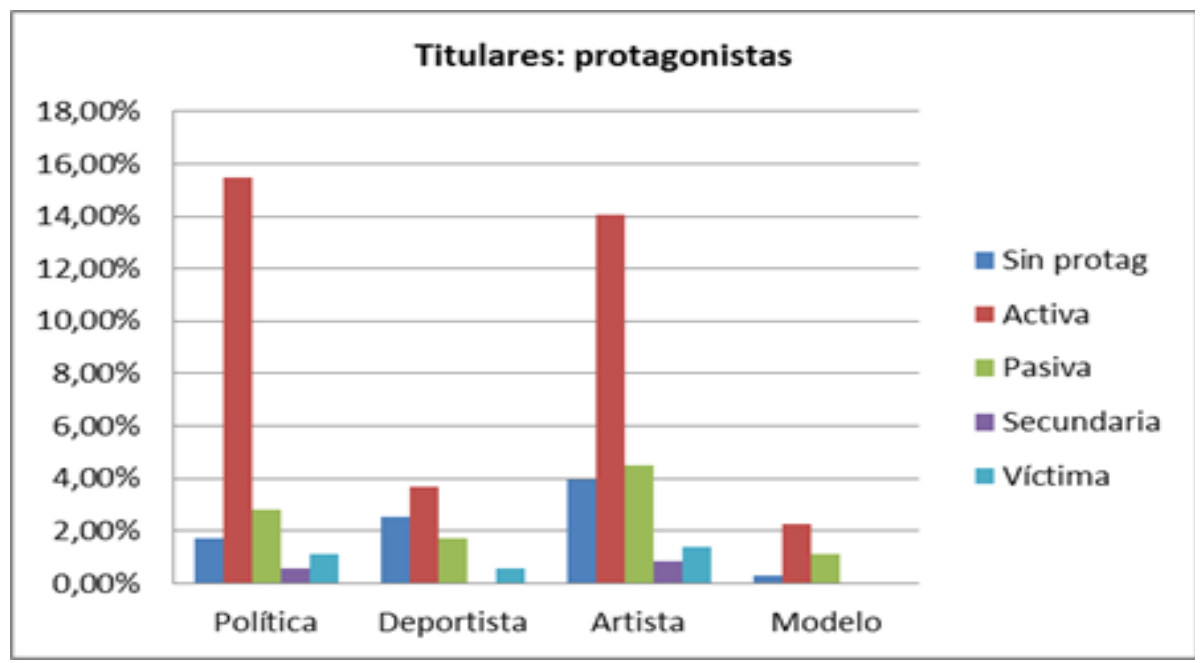

Fuente: Elaboración propia.

El objeto de análisis de esta categoría tenía por finalidad saber en qué medida las mujeres aparecían en función del cargo y también cuál era el porcentaje de mujeres que aparecían en función de su profesión. Los datos se corresponden al total de los textos analizados y de ellos se desprende que el 18,45 tienen un lugar en el periódico en función de su cargo y un 8,14 en función de su profesión. Lo cual podría poner en evidencia que o bien la Ley de Paridad no se está cumpliendo o que los cargos públicos que ostentan las mujeres tienen menos relevancia y menor repercusión en los medios de comunicación que los de los hombres. Obviamente si estos datos se refieren al total de las informaciones publicadas por los diarios, los porcentajes de presencia femenina se desploman: quedan en un 2,5 en el caso de cargos y un 1,1 por profesiones.

\subsection{Jerarquización periodística de la presencia femenina}

Otro dato redundante sobre la presencia de mujeres y los temas de género: no aparecen ni en la portada ni en la contraportada, las dos secciones más importantes del periódico. Los temas de género se merecen únicamente las páginas interiores y muchas de las protagonistas aparecen por su cargo, más que por su profesión. 
Ofa Bezunartea Valencia, Ma del Mar García Gordillo, Ana Rodríguez 249

Gráfico 14: Jerarquización periodística de la presencia femenina.

\begin{tabular}{|c|c|c|c|c|c|c|c|c|c|c|c|c|c|c|c|c|c|}
\hline 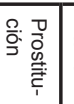 & 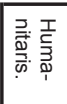 & 응 & 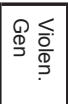 & 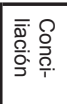 & 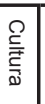 & 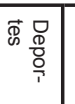 & 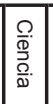 & 离 & 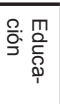 & $\mid$ & 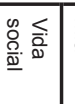 & 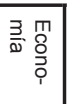 & 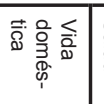 & 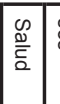 & 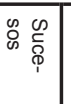 & 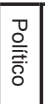 & \\
\hline $\begin{array}{l}\text { : } \\
\vdots \\
\end{array}$ & $\begin{array}{l}\text { 怘 } \\
\text { 。. } \\
\end{array}$ & $\begin{array}{l}\text { : } \\
\text { : }\end{array}$ & 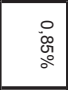 & $\vdots$ & $\begin{array}{c}0 \\
0 \\
0 \\
0\end{array}$ & $\begin{array}{l}\text { N } \\
\text { : } \\
0\end{array}$ & \begin{tabular}{|l|}
0 \\
\% \\
$\circ$
\end{tabular} & : & $\begin{array}{l}\text { \% } \\
\text { o. }\end{array}$ & \begin{tabular}{|l|}
0 \\
$\vdots$
\end{tabular} & $\begin{array}{c}0 \\
\text { on } \\
0 \\
0 \\
\end{array}$ & $\begin{array}{l}0 \\
\text { 心 } \\
\vdots \\
\end{array}$ & $\begin{array}{l}0 \\
\text { : } \\
\text { o. } \\
\end{array}$ & $\because \vdots$ & $\begin{array}{l}0 \\
0 \\
0 \\
0\end{array}$ & $\begin{array}{c}\text { 芯 } \\
\text { o. } \\
\vdots\end{array}$ & Sin profesión \\
\hline $\begin{array}{l}\text { 总 } \\
\text { : }\end{array}$ & 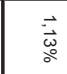 & $\begin{array}{l}\overrightarrow{\overrightarrow{\vec{\omega}}} \\
\stackrel{\circ}{\circ}\end{array}$ & $\begin{array}{l}\overrightarrow{\overrightarrow{0}} \\
\stackrel{\circ}{\circ}\end{array}$ & $\begin{array}{l}0 \\
: \\
\circ\end{array}$ & 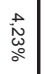 & $\begin{array}{l}\overrightarrow{\vec{A}} \\
\frac{\mathrm{A}}{\circ}\end{array}$ & \begin{tabular}{|l|} 
\\
$\vdots$ \\
$\circ$
\end{tabular} & \begin{tabular}{ll|} 
& \\
$\circ$ & $\circ$
\end{tabular} & $\begin{array}{l}\text { 芯 } \\
\text { o. }\end{array}$ & \begin{tabular}{|l|} 
\\
og \\
0
\end{tabular} & $\begin{array}{l}\vec{g} \\
\stackrel{\circ}{\circ}\end{array}$ & \begin{tabular}{l|} 
\\
总 \\
o
\end{tabular} & \begin{tabular}{l|}
0 \\
$\vdots$ \\
$\vdots$
\end{tabular} & \begin{tabular}{|l|} 
总 \\
o \\
\end{tabular} & 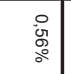 & 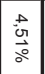 & \begin{tabular}{|l|} 
Política \\
\end{tabular} \\
\hline : & : & ஃ & $\begin{array}{l}\circ \\
\vdots \\
\vdots\end{array}$ & $\stackrel{\circ}{\circ}$ & $\begin{array}{c}0 \\
0 \\
0 \\
0 \\
0\end{array}$ & $\begin{array}{l}\circ \\
\vdots \\
\end{array}$ & $\begin{array}{l}\circ \\
\vdots \\
\circ\end{array}$ & $\begin{array}{l}\circ \\
\vdots \\
\end{array}$ & : & \begin{tabular}{|l|}
0 \\
$\vdots$ \\
\end{tabular} & $\begin{array}{c}\text { 总 } \\
\text { o. }\end{array}$ & $\begin{array}{l}0 \\
\vdots \\
\vdots\end{array}$ & $\begin{array}{l}0 \\
\vdots \\
\circ\end{array}$ & 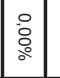 & $\begin{array}{ll} \\
\vdots \\
\circ \\
\circ\end{array}$ & 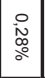 & Enseñante \\
\hline $\begin{array}{l}\circ \\
\vdots\end{array}$ & : & $\stackrel{\circ}{\circ}$ & $\begin{array}{l}\overrightarrow{\vec{\circ}} \\
\stackrel{\circ}{\circ}\end{array}$ & $\begin{array}{l}0 \\
\vdots \\
\vdots\end{array}$ & 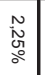 & 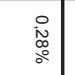 & \begin{tabular}{|l|} 
\\
$\vdots$ \\
$\vdots$
\end{tabular} & \begin{tabular}{c|c|} 
总 \\
o.
\end{tabular} & $\begin{array}{l}\text { 品 } \\
\text { ơ } \\
0\end{array}$ & \begin{tabular}{|c|} 
\\
$\vdots$ \\
$\vdots$
\end{tabular} & 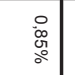 & 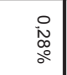 & $\begin{array}{l}0 \\
\vdots \\
\circ\end{array}$ & 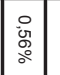 & \begin{tabular}{l}
$\stackrel{0}{0}$ \\
\multirow{2}{\circ}{}
\end{tabular} & $\begin{array}{l}\circ \\
\vdots \\
\vdots \\
0 \\
0\end{array}$ & Deportista \\
\hline : & $\begin{array}{l}\text { 胥 } \\
\text { 总 }\end{array}$ & $\begin{array}{l}\overrightarrow{\overrightarrow{\vec{\omega}}} \\
\text { o }\end{array}$ & $\begin{array}{l}\text { N } \\
\text { No } \\
\text { Ong }\end{array}$ & 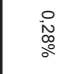 & 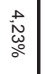 & $\begin{array}{l}\overrightarrow{0} \\
\stackrel{0}{\circ}\end{array}$ & \begin{tabular}{|l|} 
\\
$\vdots$ \\
$\circ$ \\
$\circ$
\end{tabular} & 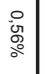 & 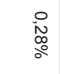 & \begin{tabular}{|l|} 
\\
$\vdots$ \\
$\circ$ \\
$\circ$
\end{tabular} & 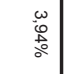 & $\begin{array}{c}0 \\
\text { 心. } \\
\text { o. } \\
0\end{array}$ & 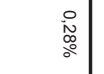 & 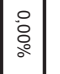 & $\begin{array}{l}0 \\
\text { on } \\
\text { o. }\end{array}$ & 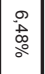 & Artista \\
\hline $\begin{array}{l}0 \\
\vdots \\
\circ\end{array}$ & ஃे & ஃ & $\begin{array}{l}0 \\
\vdots \\
\circ \\
\circ\end{array}$ & $\begin{array}{l}\text { : } \\
\vdots\end{array}$ & $\begin{array}{ll}\circ \\
:\end{array}$ & 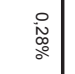 & \begin{tabular}{|c|}
$\circ$ \\
$\vdots$ \\
$\circ$
\end{tabular} & $\begin{array}{c}0 \\
\text { : } \\
\text { o. }\end{array}$ & $\begin{array}{l}\text { : } \\
\vdots\end{array}$ & \begin{tabular}{|c|} 
\\
$\vdots$ \\
$\circ$
\end{tabular} & $\begin{array}{l}\text { 总 } \\
\text { 号 }\end{array}$ & $\begin{array}{l}\circ \\
: \\
\circ \\
\circ\end{array}$ & $\begin{array}{l}0 \\
\vdots \\
\circ\end{array}$ & $\div$ & $\begin{array}{l}0 \\
\circ \\
\circ\end{array}$ & 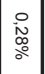 & Sanitario \\
\hline $\begin{array}{l}\circ \\
\vdots \\
\vdots\end{array}$ & : & ஃे & 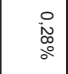 & $\begin{array}{l}\circ \\
\vdots\end{array}$ & 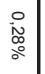 & 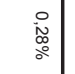 & \begin{tabular}{|l|} 
\\
$\vdots$ \\
$\circ$
\end{tabular} & 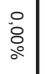 & : & \begin{tabular}{|c|} 
\\
$\vdots$ \\
$\circ$
\end{tabular} & : & $\begin{array}{l}0 \\
\vdots\end{array}$ & $\begin{array}{l}0 \\
\vdots \\
\circ\end{array}$ & 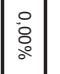 & $\begin{array}{l}\circ \\
\vdots \\
\circ\end{array}$ & \begin{tabular}{|c|}
0 \\
$\vdots$ \\
$\vdots$
\end{tabular} & Funcionario \\
\hline $\begin{array}{l}0 \\
\vdots \\
\vdots\end{array}$ & : & : & 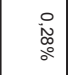 & : & $\begin{array}{c}0 \\
\text { : } \\
\vdots \\
0\end{array}$ & 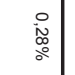 & \begin{tabular}{|c|}
$\circ$ \\
$\vdots$ \\
$\circ$
\end{tabular} & : & : & \begin{tabular}{|c|} 
\\
$\vdots$ \\
$\vdots$
\end{tabular} & ஃे & $\begin{array}{l}\circ \\
\vdots \\
\circ\end{array}$ & $\begin{array}{l}\text { : } \\
\vdots\end{array}$ & 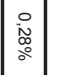 & $\begin{array}{lll} & 0 \\
\vdots\end{array}$ & : & ONG \\
\hline $\begin{array}{l}\text { : } \\
\vdots\end{array}$ & : & : & $\begin{array}{l}0 \\
\vdots \\
\vdots \\
\vdots\end{array}$ & $\begin{array}{l}\text { : } \\
\vdots\end{array}$ & $\begin{array}{ll}0 \\
:\end{array}$ & $\begin{array}{l}\text { : } \\
\text { : } \\
\text { : }\end{array}$ & \begin{tabular}{|l|} 
\\
$\vdots$ \\
$\vdots$
\end{tabular} & $\begin{array}{l}\circ \\
\vdots \\
\circ\end{array}$ & $\begin{array}{l}0 \\
\vdots \\
\circ\end{array}$ & \begin{tabular}{|c|} 
\\
$\vdots$ \\
$\vdots$
\end{tabular} & $\begin{array}{l}\text { 总 } \\
\text { 骂 }\end{array}$ & $\begin{array}{l}0 \\
\vdots \\
\vdots\end{array}$ & $\begin{array}{l}0 \\
: \\
\vdots\end{array}$ & $\begin{array}{l}\circ \\
\vdots\end{array}$ & $\begin{array}{l}0 \\
: \\
\vdots\end{array}$ & \begin{tabular}{|l|} 
\\
$\vdots$ \\
$\vdots$
\end{tabular} & Ama de casa \\
\hline \begin{tabular}{l|l}
0 \\
$\vdots$ \\
$\vdots$
\end{tabular} & : & : & $\begin{array}{c}\text { 品 } \\
\text { o. }\end{array}$ & $\begin{array}{l}\text { : } \\
\vdots\end{array}$ & $\begin{array}{lll} & \\
\vdots\end{array}$ & 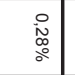 & \begin{tabular}{|l|} 
\\
$\vdots$ \\
$\vdots$
\end{tabular} & $\begin{array}{lll} & \\
\circ & \end{array}$ & $\begin{array}{l}\text { : } \\
\vdots\end{array}$ & \begin{tabular}{|c|} 
\\
$\vdots$ \\
$\vdots$
\end{tabular} & : & $\begin{array}{ll} & 0 \\
\vdots \\
\circ\end{array}$ & $\begin{array}{l:}0 \\
\vdots \\
\vdots\end{array}$ & 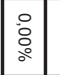 & $\begin{array}{lll} \\
\vdots\end{array}$ & \begin{tabular}{|l|} 
\\
$\vdots$ \\
$\vdots$
\end{tabular} & Empresaria \\
\hline $\begin{array}{l}\circ \\
:\end{array}$ & : & : & $\begin{array}{l}\circ \\
: \\
\circ\end{array}$ & $\begin{array}{l}\circ \\
\vdots \\
\circ\end{array}$ & $\begin{array}{c}0 \\
\text { 品 } \\
0\end{array}$ & 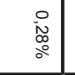 & \begin{tabular}{|l|} 
\\
$\vdots$ \\
$\vdots$ \\
$\circ$
\end{tabular} & \begin{tabular}{ll|}
$\circ$ \\
$\vdots$ \\
$\circ$
\end{tabular} & $\begin{array}{l}\circ \\
\vdots \\
\circ\end{array}$ & \begin{tabular}{|l|} 
\\
$\vdots$ \\
$\circ$ \\
\end{tabular} & : & $\begin{array}{l}\circ \\
\vdots \\
\circ \\
\circ\end{array}$ & $\begin{array}{l}\circ \\
\vdots \\
\vdots\end{array}$ & : & $\begin{array}{ll}0 \\
\vdots \\
\vdots\end{array}$ & 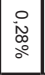 & Abogada \\
\hline $\begin{array}{l}0 \\
\vdots \\
\vdots\end{array}$ & : & $\therefore$ & $\begin{array}{l}0 \\
\vdots \\
\circ\end{array}$ & ஃ & \begin{tabular}{ll|} 
\\
$\vdots$ \\
$\circ$
\end{tabular} & $\begin{array}{ll}0 \\
\vdots \\
\circ\end{array}$ & \begin{tabular}{|c|} 
\\
$\vdots$ \\
$\circ$
\end{tabular} & $\begin{array}{l}\circ \\
\vdots\end{array}$ & ஃ & \begin{tabular}{|c|} 
\\
$\vdots$ \\
$\circ$
\end{tabular} & $\begin{array}{l}\text { 总 } \\
\text { \% }\end{array}$ & $\begin{array}{ll} & 0 \\
\vdots\end{array}$ & $\begin{array}{l}0 \\
\vdots \\
\circ\end{array}$ & : & $\begin{array}{ll} \\
\vdots \\
\vdots\end{array}$ & \begin{tabular}{|l|} 
\\
$\vdots$ \\
$\vdots$
\end{tabular} & \begin{tabular}{|l|} 
Juez \\
\end{tabular} \\
\hline $\begin{array}{l}\circ \\
:\end{array}$ & 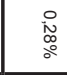 & 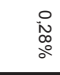 & $\begin{array}{c}0 \\
\text { 总 } \\
0\end{array}$ & $\begin{array}{l}\circ \\
\vdots \\
\circ\end{array}$ & $\begin{array}{c}0 \\
\text { 品 } \\
0\end{array}$ & $\begin{array}{l}\circ \\
\vdots \\
\circ\end{array}$ & 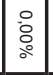 & \begin{tabular}{ll|}
$\circ$ & \\
$\circ$ &
\end{tabular} & $\begin{array}{l}\circ \\
\vdots \\
\circ\end{array}$ & \begin{tabular}{|l|} 
\\
$\circ$ \\
$\circ$
\end{tabular} & : & $\begin{array}{l}\circ \\
: \\
\circ\end{array}$ & $\begin{array}{l}\circ \\
\vdots \\
\circ\end{array}$ & : & $\begin{array}{l}0 \\
\vdots \\
\vdots\end{array}$ & $\begin{array}{c}0 \\
\text { 前 } \\
0\end{array}$ & $\begin{array}{l}\text { Denominación } \\
\text { vicaria }\end{array}$ \\
\hline 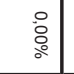 & : & 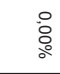 & $\begin{array}{ll}0 \\
\vdots \\
\circ\end{array}$ & $\begin{array}{l}\circ \\
\vdots \\
\circ\end{array}$ & $\begin{array}{ll}\circ \\
\vdots\end{array}$ & : & \begin{tabular}{|c|}
$\circ$ \\
$\vdots$ \\
\end{tabular} & : & : & \begin{tabular}{|l|}
$\circ$ \\
$\vdots$ \\
$\circ$
\end{tabular} & : & $\begin{array}{ll}0 \\
\vdots \\
\end{array}$ & $\begin{array}{ll}\circ \\
\vdots \\
\circ\end{array}$ & : & $\begin{array}{ll}0 \\
\vdots \\
\vdots\end{array}$ & $\begin{array}{ll}0 \\
\vdots \\
\end{array}$ & Prostitución \\
\hline$\stackrel{\circ}{\circ}$ & : & $\therefore$ & $\begin{array}{ll}\circ \\
\vdots \\
\circ\end{array}$ & : & $\begin{array}{c}: \\
\substack{0 \\
\text { o. } \\
0}\end{array}$ & $\begin{array}{ll}\circ \\
\vdots\end{array}$ & \begin{tabular}{|c|}
$\circ$ \\
$\vdots$ \\
$\circ$
\end{tabular} & : & : & $\mid \begin{array}{l}\circ \\
\vdots \\
\circ\end{array}$ & : & & & & & & Delincuente \\
\hline : & : & $\begin{array}{c}\text { 总 } \\
\text { o. } \\
\text { o }\end{array}$ & $\begin{array}{c}0 \\
\text { 总 } \\
\text { o. }\end{array}$ & : & $\begin{array}{ll}\circ \\
\vdots\end{array}$ & \begin{tabular}{l|l}
0 \\
$\vdots$
\end{tabular} & \begin{tabular}{|c|} 
\\
$\vdots$ \\
$\vdots$
\end{tabular} & : & : & \begin{tabular}{|c|} 
\\
$\vdots$ \\
$\vdots$
\end{tabular} & $\begin{array}{l}0 \\
\text { o. } \\
\text { o. } \\
0\end{array}$ & $\begin{array}{ll}0 \\
\vdots\end{array}$ & $\begin{array}{ll}0 \\
\vdots \\
\circ\end{array}$ & 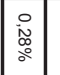 & $\begin{array}{ll}0 \\
\vdots \\
\vdots\end{array}$ & 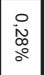 & Famoso \\
\hline$\therefore$ & $\begin{array}{l}\text { 응 } \\
\text { \% }\end{array}$ & $\therefore$ & : & : & \begin{tabular}{c|c}
0 \\
: \\
$\vdots$ \\
0
\end{tabular} & 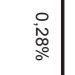 & \begin{tabular}{|c|}
$\circ$ \\
$\vdots$ \\
$\circ$
\end{tabular} & : & : & $\mid \begin{array}{l}0 \\
\vdots \\
\circ\end{array}$ & 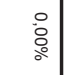 & : & $\begin{array}{ll}\circ \\
\circ\end{array}$ & 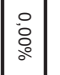 & : & \begin{tabular}{c|}
0 \\
o. \\
o.
\end{tabular} & Cientifica \\
\hline : & 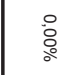 & 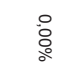 & $\begin{array}{ll}0 \\
\vdots \\
\vdots\end{array}$ & : & $\begin{array}{ll}\circ \\
\vdots \\
\circ\end{array}$ & $\begin{array}{ll}\circ \\
\vdots\end{array}$ & \begin{tabular}{|c|} 
\\
$\vdots$ \\
$\vdots$
\end{tabular} & : & : & \begin{tabular}{|c|} 
\\
$\vdots$ \\
$\vdots$
\end{tabular} & 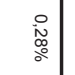 & : & $\begin{array}{ll}0 \\
\vdots \\
\circ\end{array}$ & $\div$ & $\begin{array}{ll}0 \\
\vdots\end{array}$ & \begin{tabular}{|l|} 
\\
$\vdots$ \\
\end{tabular} & Escritora \\
\hline : & : & $\therefore$ & $\begin{array}{ll}\circ \\
\vdots \\
\circ\end{array}$ & : & $\begin{array}{cc}0 \\
0 \\
0 \\
0 \\
0\end{array}$ & $\begin{array}{ll}\circ \\
\vdots \\
\vdots\end{array}$ & \begin{tabular}{|l|} 
\\
$\vdots$ \\
\end{tabular} & $\begin{array}{ll}\circ \\
\vdots\end{array}$ & : & \begin{tabular}{|l|} 
\\
$\vdots$ \\
$\circ$
\end{tabular} & $\begin{array}{l}\overrightarrow{\vec{A}} \\
\stackrel{\mathrm{\partial}}{\circ}\end{array}$ & $\begin{array}{ll}\circ \\
\vdots \\
\circ\end{array}$ & $\begin{array}{ll}\circ \\
\vdots \\
\end{array}$ & 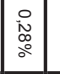 & \begin{tabular}{ll|}
$\circ$ \\
$\vdots$ \\
$\vdots$
\end{tabular} & $\begin{array}{c}0 \\
\infty \\
0 \\
0 \\
0\end{array}$ & Modelo \\
\hline : & : & : & $\begin{array}{c}0 \\
\text { o. } \\
\text { o. } \\
0\end{array}$ & : & $\begin{array}{ll}\circ \\
\vdots \\
\circ\end{array}$ & 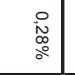 & \begin{tabular}{|l|} 
\\
$\vdots$ \\
$\circ$
\end{tabular} & : & : & \begin{tabular}{|l|} 
\\
$\vdots$ \\
\end{tabular} & $\overrightarrow{\overrightarrow{\vec{\omega}}}$ & $\begin{array}{ll}\circ \\
\vdots \\
0\end{array}$ & \begin{tabular}{l|}
$\circ$ \\
$\vdots$ \\
$\circ$
\end{tabular} & 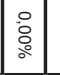 & $\begin{array}{ll}\circ \\
\vdots \\
\vdots\end{array}$ & $\begin{array}{cc}0 \\
0 \\
\text { o. } \\
\text { o. }\end{array}$ & Periodista \\
\hline 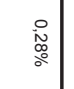 & 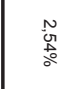 & $\begin{array}{l}\text { 岁 } \\
\text { 。 }\end{array}$ & 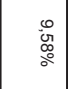 & 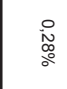 & 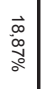 & 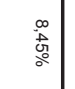 & $\mid \begin{array}{l}\stackrel{0}{0} \\
\text { o. } \\
\circ\end{array}$ & 吾 & 总 & \begin{tabular}{|c|} 
\\
总 \\
0
\end{tabular} & 㕝 & 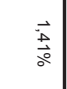 & $\begin{array}{l}\text { 응 } \\
\text { : } \\
\text { o }\end{array}$ & $\vec{~}$ & 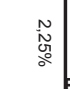 & 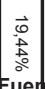 & TOTAL \\
\hline
\end{tabular}




\subsection{Protagonista según cargo y profesión por sección}

Gráfico 15: Protagonista según cargo y profesión por sección.

Temas

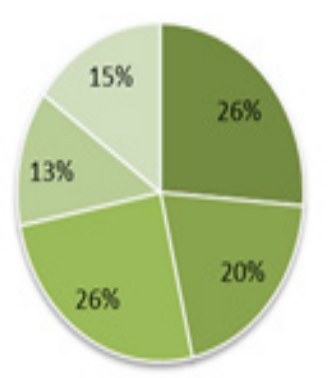

Profesiones

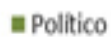

"Vida social

$=$ Cultura

= Violencia Género

Género

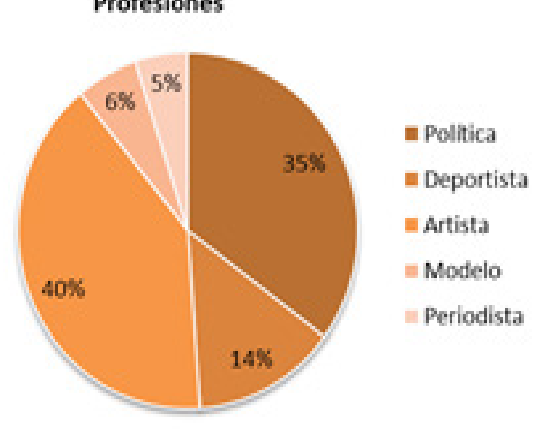

\begin{tabular}{|l|c|c|c|c|c|}
\hline & \multicolumn{5}{|c|}{ Profesiones } \\
\hline TEMAS & Política & Deportista & Artista & Modelo & Periodista \\
\hline Político & $4,51 \%$ & $0,85 \%$ & $6,48 \%$ & $0,85 \%$ & $0,28 \%$ \\
\hline Vida social & $1,97 \%$ & $0,85 \%$ & $3,94 \%$ & $1,41 \%$ & $1,13 \%$ \\
\hline Cultura & $4,23 \%$ & $2,25 \%$ & $4,23 \%$ & $0,85 \%$ & $0,00 \%$ \\
\hline $\begin{array}{l}\text { Violencia } \\
\text { Género }\end{array}$ & $1,69 \%$ & $1,69 \%$ & $2,25 \%$ & $0,00 \%$ & $0,85 \%$ \\
\hline Género & $2,54 \%$ & $0,56 \%$ & $1,97 \%$ & $0,28 \%$ & $0,56 \%$ \\
\hline Promedio & $21,69 \%$ & $8,45 \%$ & $24,79 \%$ & $3,66 \%$ & $3,10 \%$ \\
\hline
\end{tabular}

Resumen de temas y profesiones

Fuente: Elaboración propia.

Los resultados de esta categoría de análisis son aún más expresivos si se refieren los resultados al total de noticias publicadas por los periódicos: como puede verse en el gráfico las protagonistas femeninas no consiguen llegar al dígito en ninguna de las secciones. El único porcentaje que supera esta barrera con casi un $4 \%$ es en local y se refiere a temas de género puesto que responde a la categoría "sin protagonista". 
Ofa Bezunartea Valencia, Ma del Mar García Gordillo, Ana Rodríguez 251

\subsection{Firma y diarios}

Gráfico 16: Firmas femeninas por diario.

\begin{tabular}{|l|c|c|c|}
\hline & Cargo & Profesión & Sin protagonista \\
\hline El Correo de Andalucía & $31,73 \%$ & $7,69 \%$ & $60,58 \%$ \\
\hline Diario de Sevilla & $9,02 \%$ & $9,02 \%$ & $81,97 \%$ \\
\hline Málaga Hoy & $10,00 \%$ & $5,45 \%$ & $84,55 \%$ \\
\hline La Voz de Cádiz & $25,00 \%$ & $10,80 \%$ & $63,07 \%$ \\
\hline Huelva Información & $15,04 \%$ & $3,76 \%$ & $81,20 \%$ \\
\hline Granada Hoy & $18,44 \%$ & $10,64 \%$ & $70,92 \%$ \\
\hline TOTAL & $18,45 \%$ & $8,14 \%$ & $73,16 \%$ \\
\hline
\end{tabular}

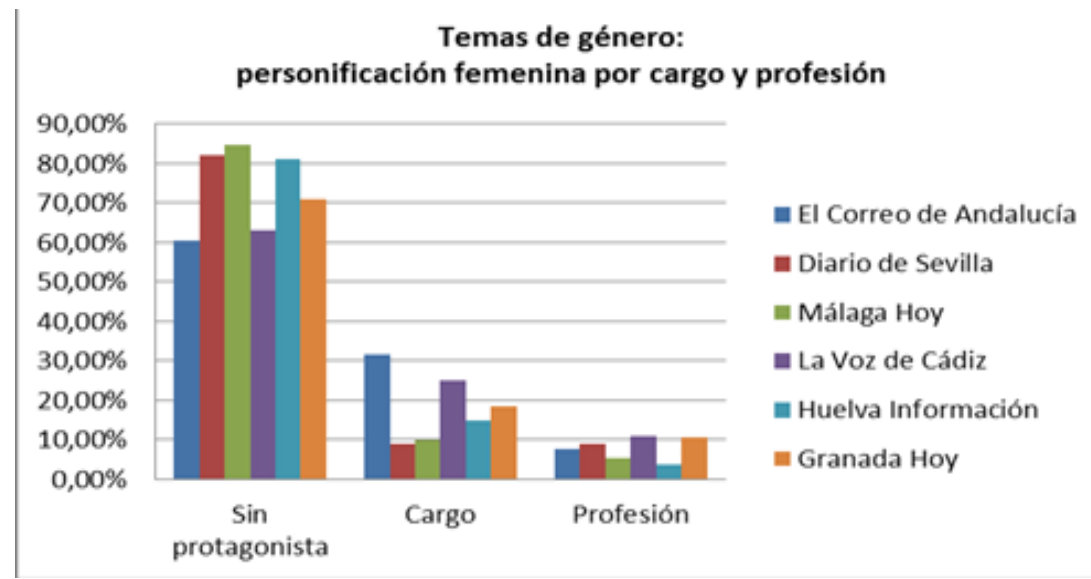

Temas de género:

personificación femenina por cargo y profesión

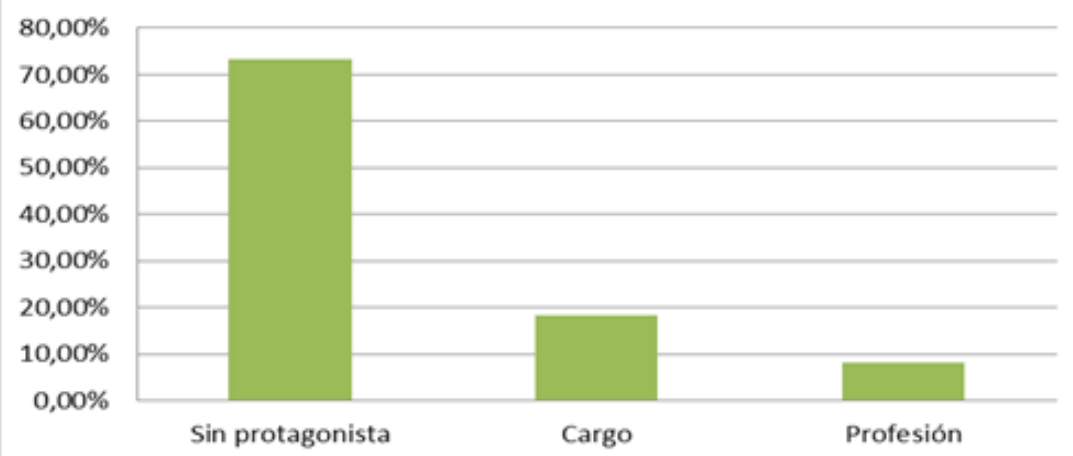

Cruce de mujeres según cargo y profesión

Fuente: Elaboración propia. 
La mujer como cargo y como fuente en la prensa escrita.

La paridad no llega a las noticias

Otro plano de análisis de los periódicos desde la perspectiva de género, conocida la notable presencia de las periodistas en las redacciones, especialmente como redactoras, era hacer un seguimiento de las firmas de las informaciones: un modo de comprobar qué grado de paridad se produce en las redacciones de los periódicos tanto desde el punto de vista cuantitativo, como sobre todo cualitativo.

Aunque es preciso hacer la salvedad de que una parte de los temas publicados por los diarios llevan la firma del medio, y otra parte también llevan la referencia de agencia y en ninguno de los casos se especifica el nombre del redactor, lo cierto es que en el conjunto de los diarios, la visibilidad de las firmas de las redactoras es muy limitada: del total de noticias de los periódicos (6.670) las firmas de mujeres, el promedio no alcanza el $10 \%$. Aunque hay diferencias reseñables entre unos y otros diarios: Diario de Sevilla apenas alcanza el 7,5\%, mientras que El Correo de Andalucía llega al $12,7 \%$, lo cierto es que todas son cifras muy bajas.

Todavía se afina más en el análisis del reconocimiento profesional de las periodistas en el recorrido por las secciones. La cualificación profesional y el rango de los periodistas se clasifica en función de los espacios de mayor relevancia - la primera página o portada y la contraportada, son los escaparates de un periódico- y por las secciones en las que se distinguen las de primera categoría, aquellas que contienen las noticias de mayor transcendencia: economía, política, (entendiendo como tal lo referente a los gobiernos nacionales y autonómicos, parlamentos y ejecutivas de los partidos y la política internacional) y las columnas de opinión; las de una categoría intermedia, tales como local, sociedad, y por último las secciones de cotilleo, como televisión, incluso cultura en la medida que buena parte de ella se refiere al mundo del espectáculo y en no pocas ocasiones ocupa un lugar en las páginas no por su contenido creativo, sino por las vidas privadas de las estrellas o por el atractivo de las imágenes. Una clasificación que se corresponde con lo que periodísticamente se denominan noticias duras y noticias blandas; esto es: las primeras, imprescindibles para quien se considere bien informado y las segundas, perfectamente prescindibles. Bien es cierto que tal clasificación encaja plenamente en los estereotipos masculinos respecto de lo que es importante, pues en las noticias blandas se incluyen los temas de interés humano, los procesos sociales, más que los acontecimientos concretos, muchas de las cuestiones vitales que subyacen en las preocupaciones colectivas y que no siempre emergen como noticias.

Pues bien, como puede apreciarse en las tablas, no había firmas de periodistas ni en la primera página ni en la contraportada, los dos grandes escaparates, salvo exiguos testimonios en las portadas de Málaga Hoy y del Diario de Cádiz. En la sección más intelectual, opinión, las firmas de mujeres en ningún caso superan el $8 \%$. La sección más relevante en firmas de mujeres es la de local, donde destacan Granada Hoy y Diario de Cádiz en los que las firmas femeninas sobrepasan el $25 \%$., le sigue Andalucía que en cierto modo tiene un predominio de noticias que pudiéramos asociar a local, mientras que en el resto de secciones las firmas de mujeres son muy minoritarias. 
Ofa Bezunartea Valencia, Ma del Mar García Gordillo, Ana Rodríguez 253

Gráfico 17: Firma femenina por diario y sección.

\begin{tabular}{|l|c|c|c|}
\hline & Sin protagonista & Cargo & Profesión \\
\hline Portada & $0,488 \%$ & $0,000 \%$ & $0,244 \%$ \\
\hline Interior & $67,317 \%$ & $17,683 \%$ & $7,561 \%$ \\
\hline Contraportada & $1,220 \%$ & $0,000 \%$ & $0,000 \%$ \\
\hline
\end{tabular}

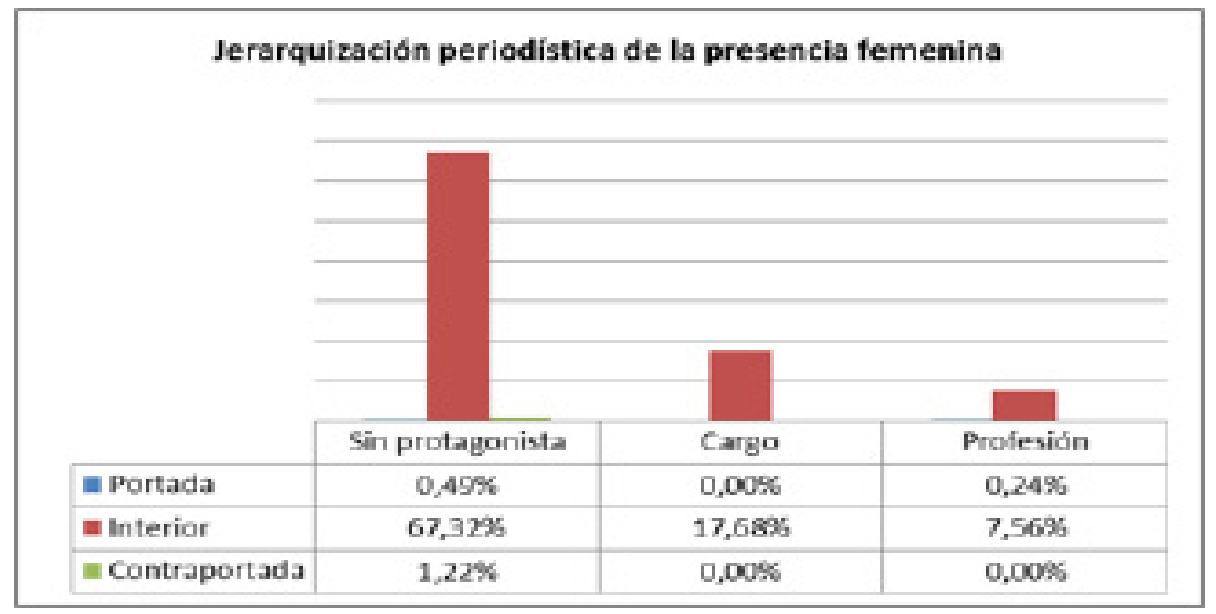

Fuente: Elaboración propia.

\section{DISCUSIÓN}

Los datos hasta aquí reseñados hablan por sí solos: la paridad no existe en los medios de comunicación. Así ha quedado recogido en cada una de las categorías que se han analizado en esta investigación.

Sólo el $6 \%$ de los textos publicados por los 42 ejemplares de diarios analizados trataban temas de género o estaban protagonizados por mujeres. En ellos, únicamente un $19 \%$ de las protagonistas eran políticas, mientras que la cultura y la vida social sumaban casi un $30 \%$, datos que casi se reproducen si los extrapolamos a la presencia de la mujer en los distintos ámbitos profesionales: las políticas mantienen la cifra, artistas, modelos y famosas alcanzan el $32 \%$. Ciertamente el impacto de las vidas privadas de ciertas profesionales tiene más peso informativo que el de entornos como el de la administración pública, la universidad, la educación, la ciencia, la justicia, la sanidad,... es decir, el de cientos de miles de mujeres que acuden a diario a sus puestos de trabajo.

Las mujeres no sólo no están en los medios como protagonistas de las noticias, tampoco tienen peso como fuentes de información, ni en función de los cargos que ocupan ni de las profesiones que desempeñan. La visibilidad femenina es calificable de ridícula atendiendo a los porcentajes que hemos expuesto.

Queda concluir que o bien la Ley de Igualdad o Paridad no se está cumpliendo 
La mujer como cargo y como fuente en la prensa escrita.

La paridad no llega a las noticias

o bien no está logrando su objetivo. Los porcentajes de visibilidad de las mujeres profesionales se mide en centésimas y los medios de comunicación exhiben un mundo desproporcionadamente masculinizado.

\section{REFERENCIAS BIBLIOGRÁFICAS}

ARMSTRONG, Cory L. (2006): "Writing about women: an examination of how content for women is determined in newspapers", Mass Communication and Society, vol.9, nº4, pp. 447460. Disponible en http://dx.doi.org/10.1207/s15327825mcs0904_4

ARMSTRONG, Cory L.; Nelson, Michelle R. (2005): "How newspaper sources trigger gender stereotypes", Journalism and Mass Communication Quaterly, vol.82, n4, pp. 820-837.

BACCH, M; Altés Rufías, E; Gallego Ayala, J. y otras (2000): El sexo de la noticia. Barcelona: Icaria

BEZUNARTEA, Ofa. (1988) Noticias e ideología profesional. La prensa vasca en la transición política. Bilbao: Ediciones Deusto.

BLANCO CASTILLA, E. (2005). "Mujer y poder en los medios: Dificultades para una incorporación plena", Informe anual de la profesión periodística 2005. Madrid: Asociación de la prensa

BROWN, Morris Jr. (2006): "Women making news: gender and journalism in modern Britain", Newspaper Research Journal, vol. 27, n²2. Disponible en http://vlex.com/vid/making-gnederjournalism-modern-britain-61541810

BRUIN, M. y ROSS, K (eds) (2004). Gender and Newsroom Cultures: Identities at Work. Creskill, NJ: Hampton Press

BURKE, R.J. and STONG, M. (2009) 'Workaholism Among Norwegian Journalists: Gender Differences', Equal Opportunities International 28 (6), pp. 452-464.

CANEL, Maria José (2000) Periodistas al Descubierto. Madrid: Centro de Investigaciones Sociológicas.

CRAFT, S. and WANTA, W. (2004): "Women in the newsroom: influences of female editors and reporters on the news agende", Journalism and Mass Communication Quaterly, vol. 1, pp. 124-138 Disponible en http://dx.doi.org/10.1207/s15327825mcs0803_5

DJERF-PIERRE, M. (2007) 'The Gender of Journalism', Nordicom Review, pp. 81-104

EILEEN Mahoney (2000). "Mujeres, desarrollo y medios de comunicación" Revista TELOS, No 31.

FARIAS, Pedro (2009) Informe Anual de la Profesión Periodística. Madrid: Asociación de la Prensa de Madrid.

FISHMAN, Mark (1980) Manufacturing the news. Austin \& London: University of Texas Press, Texas.

FRANQUET, Rosa (2005): Representación de género en los principales medios de comunicación on line. Madrid: Instituto de la mujer.

-(1992) 'Mujer y rutinas de producción en radio y televisión' en La investigación en la comunicación, Madrid: III Simposio de la Asociación de Investigadores en Comunicacion, AICE.

FREEDMAN, Eric; FICO, Frederick (2005): "Male and female sources in newspaper coverage of male and female candidates in open races for governor in 2002", Mass Communication and Society, vol.8, nº 3 , pp. 257-272.

FREEDMAN, Eric; FICO, Frederick; LOVE, Brad (2007): "Male and female sources in newspaper coverage of male and female candidates in US Senate races in 2004", Journal of Women, Politics \& Policy, vol.29, nº1, pp. 57-76.

GALLAGHER, , M. (2005): ¿Quién figura en las noticias? Proyecto Global de Monitoreo de 
Medios. Disponible en http://www.whomakesthenews.org

GALLEGO, Juana (2010): "De reinas a ciudadanas. Género, comunicación y cambio social", II Jornadas sobre mujeres y medios de )Comunicación. Universidad el País Vasco, PP. 5-27. GANS, Herbert J.( 1980) Deciding What's news, Vintage Books, London.

GARCÍA DE CORTÁZAR, M. and GARCÍA DE LEÓN, M.A. (Coords.) (2000). Profesionales del Periodismo. Hombres y Mujeres en los Medios de Comunicación. Madrid: Centro De Investigaciones Sociológicas. Colección Monografías, Núm. 181

HOOBLER, J.M., LEMMON, G, \& WAYNE, S.J. (2009) 'Bosses' Perceptions of Family-Work Conflict and Women's Promotability: Glass Ceiling Effects'. Academy of management Journal, 52 (5), pp. 939--957

HUMANES, Maria Luisa. (2003) 'Evolución de Roles y Actitudes. Cultura y Modelos Profesionales del Periodismo'. Telos, 54 (Enero-Marzo), Available at: Http://Www.Campusred. Net/Telos

LAVIE, Aliza; LEHMAN-WILZIG, Sam (2003): "Whose news?:Does gender determine the editorial product?", European Journal of Communication, vol.18, n5. Disponible en http://ejc. sagepub.com/content/18/1/5/

LAVIE, Aliza; LEHMAN-WILZIG, Sam (2005): "The method is the message: Explaining inconsistent findings in gender and news production research", Journalism, vol.6, pág.66-89. Disponible en http://jou.sagepub.com/content/6/1/66

LIAMPUTTONG, P. \& EZZY, D. (2005) Qualitative Research Methods (Second edition), Oxford University Press, Melbourne,.

LIPPMANN, Walter (2002) La Opinión Pública. Langre, Madrid.

LÓPEZ DÍEZ, Pilar. (2004) 'El Techo de Cristal También Existe en los Medios', disponible en: Http://Mujeres.Usal.Es/Data/Core/Archivos/Congresoint.Doc, Access October 2004.

LOPEZ GONZÁLEZ, M. José (2002): “L'image des femmes dans les mèdias”, Informe de la Comisión Europea. Documento 9394.

MATEOS DE COBO, Ruth (2007): La presencia de estereotipos en los medios de comunicación. Análisis de la prensa digital española. Comunidad de Madrid.

McCOMBS, , Maxwell.(2006) Estableciendo la agenda. El impacto de los medios en la opinión pública y en el conocimiento, Barcelona: Paidós comunicación.

MELING-GIGGINS, M. (2001) 'Coping With Journalism: Gendered Newsroom Culture'. Jornadas de Discusión sobre la Construcción de los Estereotipos de Género en los Medios de Comunicación. Facultat de Ciències de la Comunicació, UAB

MENÉNDEZ, María Isabel. (2003) El Cuarto Poder ¿Un Poder De Mujeres?, Milenta, Oviedo. REINARDY, Scott (2009); "Female journalists more likely to leave newspapers", Newspaper Research Journal, vol. 30, $\mathrm{n}^{\circ} 3$. Disponible en http://vlex.com/vid/female-journaists-leavenewspapers-211026731

RODRÍGUEZ, Roberto. (2003) 'Características Socio-Demográficas y Laborales de los Periodistas Españoles: Índice de Satisfacción Profesional', Ámbitos, Núm. Especial 9-10, pp. 487-504.

SORIANO, J., CANTÓN, M. J. y DÍEZ, M. (2005): "La pseudofeminización de la profesión periodística en España". Zer, 19, 2005, p. 35-52

SORIANO, J., CANTÓN, M. J., DÍEZ, M. \& GIMÉNEZ, D. (2004) RadiografiaF Prèvia al Llibre Blanc de la Professió Periodística a Catalunya, Collegi de Periodistes de Catalunya, Barcelona.

VAN ZOONEN, Liesbet. (1994) Feminist Media Studies, Sage, London.

VAN ZOONEN, Lisbeth, (1991). Feminist media studies. London: Sage Publications ZOCH, , Lynn M.; VAN SLYKE TURK, Judy (1998): "Woman making news: gemder as a variable in source selection and use", Journalism and Mass Communication Quaterly, vol.75, $\mathrm{n}^{\circ} 4$, pág.762-775. 


\section{Breve semblanza de las autoras}

Ofa Bezunartea Valencia es Catedrática de Periodismo de la Universidad del País Vasco y ha desarrollado una dilatada labor docente e investigadora sobre periodística, información política, redacción, estudios de agenda y fuentes. Es miembro del Grupo de Investigación Estudio de Medios para un Periodismo de Calidad. En los últimos años ha trabajado en el I+D+i SANIMUEI financiado por el Instituto de la Mujer sobre la imagen que los medios de comunicación impresos proyectan de las mujeres.

María del Mar García Gordillo es Profesora Contratada Doctora de la Facultad de Comunicación de la Universidad de Sevilla y ha desarrollado su labor docente e investigadora en el ámbito del Periodismo Especializado. Actualmente dirige el Grupo de Investigación de Estudio de Medios para un Periodismo de Calidad y ha trabajado en el I+D+i SANIMUEI financiado por el Instituto de la Mujer sobre la imagen que los medios de comunicación impresos proyectan de las mujeres.

Ana Rodríguez Rey es doctoranda del Departamento de Periodismo II de la Facultad de Comunicación de la Universidad de Sevilla. Realiza sus investigaciones en el ámbito del Periodismo Especializado. Pertenece al Grupo de Investigación Estudio de Medios para un Periodismo de Calidad y trabaja en el I+D+i SANIMUEI financiado por el Instituto de la Mujer sobre la imagen que los medios de comunicación impresos proyectan de las mujeres.

(Recibido el 04-09-2011; aceptado el 03-01-2012) 